\title{
Do real balance effects invalidate the Taylor principle in closed and open economies?
}

Article

Accepted Version

McKnight, S. and Mihailov, A. (2015) Do real balance effects invalidate the Taylor principle in closed and open economies? Economica, 82 (328). pp. 938-975. ISSN 1468-0335 doi: https://doi.org/10.1111/ecca.12134 Available at https://centaur.reading.ac.uk/37700/

It is advisable to refer to the publisher's version if you intend to cite from the work. See Guidance on citing.

Published version at: http://onlinelibrary.wiley.com/doi/10.1111/ecca.12134/abstract

To link to this article DOI: http://dx.doi.org/10.1111/ecca.12134

Publisher: Wiley-Blackwell

All outputs in CentAUR are protected by Intellectual Property Rights law, including copyright law. Copyright and IPR is retained by the creators or other copyright holders. Terms and conditions for use of this material are defined in the End User Agreement.

www.reading.ac.uk/centaur 
Central Archive at the University of Reading

Reading's research outputs online 


\title{
Do Real Balance Effects Invalidate the Taylor Principle in Closed and Open Economies?
}

\author{
Stephen McKnight* \\ Alexander Mihailov ${ }^{\dagger}$ \\ El Colegio de México \\ University of Reading
}

September 2014

\begin{abstract}
This paper examines the determinacy implications of forecast-based monetary policy rules which set the interest rate in response to expected future inflation in a NeoWicksellian model that incorporates real balance effects. We show that the presence of such effects in closed economies restricts the ability of the Taylor principle to prevent indeterminacy of the rational expectations equilibrium, due to a cost channel of monetary policy. The problem is exacerbated in open economies, particulary if the policy rule reacts to consumer-price, rather than domestic-price, inflation. However, we show that determinacy can be achieved in both closed and open economies with the addition of monetary policy inertia.
\end{abstract}

JEL Classification: E41; E52; F41

Keywords: Equilibrium Determinacy; Real Balance Effects; Trade Openness; ForecastBased Instrument Rules; Taylor Principle; Monetary Policy Inertia.

* Centro de Estudios Económicos, El Colegio de México, Camino al Ajusco 20, Col. Pedregal de Santa Teresa, México D.F., C.P. 10740, Mexico. E-mail: mcknight@colmex.mx.

${ }^{\dagger}$ Department of Economics, University of Reading, Whiteknights, PO Box 218, Reading, RG6 6AA, United Kingdom. E-mail: a.mihailov@reading.ac.uk. 


\section{Introduction}

The importance of forward-looking monetary policy has long been emphasized by researchers. The need to conduct monetary policy in a forward-looking, or preemptive manner, arises primarily because of the widely documented long and variable time lag after which a monetary policy action takes effect in the economy (Friedman, 1968). But it has also been theoretically rationalized on the grounds of central bank credibility, in order to anchor private-sector expectations (see, e.g., Svensson, 1997; Batini and Haldane, 1999). Such benefits have not been overlooked by policymakers. Empirical evidence suggests that many central banks set the nominal interest rate in response to expected future inflation (see, e.g., Clarida et al., 1998, 2000; Orphanides, 2001, 2004; Mihailov, 2006).

A key issue in the design of such forward-looking monetary policy then, when operationalized via simple instrument rules, is that the particular interest-rate feedback rule adopted by a central bank should ensure a determinate equilibrium. ${ }^{1}$ That is, monetary policy should be designed to avoid generating indeterminacy which can destabilize the economy through the emergence of sunspot equilibria and self-fulfilling expectations that result in large reductions in the welfare of the economy. ${ }^{2}$ It has been well established in the NeoWicksellian (or New Keynesian) literature that under the Taylor principle, i.e., a policy that adjusts the nominal interest rate by proportionally more than the increase in inflation, a central bank can easily prevent the emergence of indeterminacy, provided it is not overly aggressive in its response to expected future inflation; or alternatively, by also including contemporaneous output into the feedback rule (see, e.g., Bernanke and Woodford, 1997; Clarida et al., 2000; Woodford, 2003a). These forecast-based interest-rate rules - that also respond to current output - have additionally been shown to perform well in terms of welfare. They are a good approximation of the optimal monetary policy for a central bank that has a quadratic loss function over inflation and output (see, e.g., Clarida et al., 1999), and for a broad class of Neo-Wicksellian model economies, their welfare performance is robust (see,

\footnotetext{
${ }^{1}$ We focus on simple instrument rules and not on optimal targeting rules. For a discussion on the benefits of considering simple instrument rules see, e.g., Taylor (1993), Batini and Haldane (1999), Woodford (2001), Taylor and Williams (2010). See Svensson (2003) for a consideration of optimal targeting rules.

${ }^{2}$ Our interest is in real indeterminacy rather than nominal indeterminacy. By real indeterminacy we mean that there exists a continuum of equilibrium paths, starting from the same initial conditions, which converge to the steady state. Our attention rests solely with the consideration of local (real) determinacy as opposed to global determinacy. For further discussion of these issues see Clarida et al. (2000), Carlstrom and Fuerst (2001), Woodford (2003a), and Cochrane (2011).
} 
e.g., Taylor and Williams, 2010) and in line with optimal targeting rules (see, e.g., Giannoni and Woodford, 2005). ${ }^{3}$ Recent studies have considered whether such interest-rate policies are also consistent with equilibrium determinacy in open economies. ${ }^{4}$ This literature has found that the Taylor principle may not be as effective in preventing indeterminacy in open economies if the central bank reacts to expected future consumer-price inflation, rather than expected future domestic-price inflation, since in the former the Taylor principle now becomes constrained by the economy's degree of openness to international trade. ${ }^{5}$ However, if the policy rule also responds to the real exchange rate, this can help in alleviating the indeterminacy problem for open economies (see, e.g., Linnemann and Schabert, 2006; Llosa and Tuesta, 2008; McKnight, 2011a).

A general criticism of the above literature is the notable absence of monetary aggregates from the determinacy analysis. ${ }^{6}$ In these studies, the transmission mechanism of monetary policy in a closed economy operates entirely through an aggregate demand channel: changes in the nominal interest rate affect output via changes in the real interest rate, which results in a change in inflation via a New Keynesian version of the Phillips curve. ${ }^{7}$ In this paper we show that money demand plays a crucial role for equilibrium determination even when the interest rate is the monetary policy instrument. Indeed, there are strong intuitive reasons for considering the real balance effects of money and their role in the monetary transmission mechanism. Since the classical works of Von Haberler (1937), de Scitovszky (1941), Pigou (1941, 1943), and Patinkin (1949, 1956), it has long been suggested that changes in real money balances can affect consumption and output through changes in individual wealth. Another real balance effect of money arises from facilitating transactions services. As stressed by Woodford (2003a), if money is considered to provide transaction

\footnotetext{
${ }^{3}$ Levin et al. (2003) find that instrument rules responding up to a one-year ahead inflation forecast and to current output are robust to model uncertainty, whereas rules with longer forecast horizons are less robust and prone to generating indeterminacy.

${ }^{4}$ See, e.g., Zanna (2003), Batini et al. (2004), De Fiore and Liu (2005), Linnemann and Schabert (2006), Benigno and Benigno (2008), Llosa and Tuesta (2008), Leith and Wren-Lewis (2009), Bullard and Schaling (2009), McKnight (2011a, 2011b).

5 This conclusion complements the studies of Clarida et al. (2002) and Galí and Monacelli (2005) who show that an instrument rule that responds to domestic-price inflation welfare dominates a similar rule that reacts to consumer-price inflation. However, Benigno and Benigno (2006) derive the conditions under which consumer-price inflation can be a component of the optimal targeting rule under international monetary policy cooperation.

${ }^{6}$ These studies either assume a cashless economy or adopt a money-in-the-utility function model with separability between real money balances and other arguments.

${ }^{7}$ In the open economy there is an additional monetary transmission channel that arises through changes in the terms of trade. Now changes in the nominal interest rate also affect output (and thus inflation) via an expenditure switching effect towards/away from foreign goods.
} 
services then the benefits of this service should be related to the individual's volume of transactions. Empirical estimates suggest that such effects, while small, are found to exist in the data. ${ }^{8}$

While there is a large literature that explores the determinacy properties of interest-rate rules, our contribution is to consider the robustness of the Taylor principle in closed and open economies when real balance effects of transactions services are explicitly modeled. Similar to Woodford (2003a) and Kurozumi (2006), these effects are introduced via money-in-theutility-function (MIUF) where consumption and real money balances enter non-separably. ${ }^{9}$ Now there is an additional monetary transmission mechanism, a cost channel, where changes in the nominal interest rate result in changes in the demand for money, which affects the output and pricing decisions of firms, via changes in the real marginal cost of production. The analysis therefore examines whether empirically plausible real balance effects can have important implications for determinacy of the rational expectations equilibrium in both closed and open economies. We begin by showing that, for closed economies, the presence of real balance effects increases the severity of indeterminacy under the Taylor principle. This is first demonstrated for feedback rules that set the nominal interest rate in response solely to expected future inflation (strict inflation targeting), and then shown to be robust when contemporaneous, or future output is also incorporated into the feedback rule (flexible inflation targeting). Next, we investigate the determinacy implications of real balance effects for open economies, where the feedback rule can respond to either domestic-price or consumer-price inflation. Consistent with the empirical studies of Clarida et al. (1998, 2000), Orphanides (2004) and Mihailov (2006), we focus our attention on a feedback rule that reacts to expected future inflation and contemporaneous output. In general, we find that in the presence of real balance effects the problem of indeterminacy is more severe for open economies than closed economies. When the indicator of inflation used in the policy rule is domestic-price inflation, we find that the cost channel of monetary policy increases the range of indeterminacy as the degree of trade openness decreases. However, by reacting to consumer-price inflation, not only does the range of indeterminacy increase sizeably - relative to reacting to domestic-price inflation - but the range of indeterminacy is

${ }^{8}$ See, e.g., Woodford (2003a) and Ireland (2004) using US data, Andrés et al. (2006) using Euro-area data, and Kremer et al. (2003) using German data.

${ }^{9}$ Alternatively, Andrés et al. (2009) generate real balance effects through the introduction of portfolio adjustment costs (in terms of real money balances). 
now increasing with respect to the degree of trade openness. Moreover, reacting also to the real exchange rate cannot alleviate the indeterminacy problem associated with real balance effects. Instead, we show that for both closed and open economies policy inertia can help mitigate the indeterminacy problem either in the form of interest-rate smoothing or under a speed-limit feedback rule, as originally proposed by Walsh (2003).

The current paper is related to the literature that has been studying the implications for equilibrium determinacy in closed economies when the real balance effects of transactions services are introduced through the assumption of non-separability of the utility function (between consumption and real money balances). Under a contemporaneous inflation policy rule specification, Schabert and Stoltenberg (2005) and Kurozumi (2006) employing a discrete-time MIUF model, and Benhabib et al. (2001) employing a continuous-time MIUF model, all find that real balance effects have no implications for determinacy of the rational expectations equilibrium. However, Kurozumi (2006) shows that real balance effects can be destabilizing if the policy rule responds, in addition to current inflation, also to current output. ${ }^{10,11}$ Our paper's contribution to the existing literature is twofold. Previous studies have focused exclusively on the determinacy implications of real balance effects under contemporaneous interest-rate rules. Therefore, the first contribution of this paper is that it fills an important gap in the literature by examining the determinacy implications of real balance effects under a variety of forecast-based, empirically motivated feedback rules that should be of interest to policymakers. We show that the indeterminacy implications of real balance effects are more severe when interest rate policy is forward-looking rather than contemporaneous-looking. When policy is forward-looking, self-fulfilling inflation expectations can arise, via a cost channel of monetary policy, if the monetary authority is overly-aggressive in responding to expected future inflation. The more flexible are prices in the economy the narrower is the policymaker's range of response to expected future inflation that can avoid indeterminacy. Secondly, under the cost channel adding a response to output in the policy rule weakens the magnitude of the response of the nominal interest rate to anticipated future inflation. Therefore, the lower bound on the inflation response

\footnotetext{
${ }^{10}$ Kurozumi (2006) also highlights that transaction frictions can play an important role in inducing indeterminacy. By extending the analysis of Carlstrom and Fuerst (2001) to allow for real balance effects, he shows that different timing assumptions on how money balances enter the utility function can alter the conditions for determinacy. A similar point is also made by Schabert and Stoltenberg (2005) and Stoltenberg (2012).

${ }^{11}$ For a similar feedback rule, Piergallini (2006) finds that when consumers are assumed to be finite-lived then real balance effects could actually have a stabilizing effect on the rational expectations equilibrium.
} 
coefficient needs to be greater than the Taylor principle to prevent indeterminacy.

The second contribution of this paper is that we also consider the determinacy implications of real balance effects for open economies. This is a highly significant issue in the design of interest rate policy, given the large and increasing trade share of many inflationtargeting countries (De Fiore and Liu, 2005). ${ }^{12}$ Our results suggest that open economies are particularly prone to indeterminacy with real balance effects when the central bank targets consumer-price inflation in the conduct of forecast-based monetary policy. This is important since, as discussed by Hammond (2012), all 27 inflation-targeting central banks currently use a headline consumer-price inflation measure as their operational target. Furthermore, in the presence of real balance effects the solution to alleviating the indeterminacy problem lies not with policy responding to the exchange rate, but rather with the need for policy inertia. Consequently, the remedies for restoring equilibrium determinacy under the Taylor principle are the same for both closed and open economies alike. It is shown that both a speed-limit rule that features a response to observed output growth or a policy of interest rate smoothing can help ameliorate the indeterminacy problem.

The remainder of the paper is organized as follows. Section 2 outlines the model and Section 3 discusses the linearized equilibrium system. The determinacy analysis for closed economies is addressed in Section 4. Section 5 derives the conditions for determinacy in an open-economy context and proposes an amendment to the feedback rules studied earlier, which eliminates the identified indeterminacy problem. Finally, Section 6 concludes.

\section{Model}

The model is a two-country extension of the Neo-Wicksellian MIUF model employed by Woodford (2003a) and Kurozumi (2006) for the closed economy. Within each country there exists a representative infinitely-lived household, a representative final-good producer, a continuum of intermediate-goods producing firms, and a monetary authority. Real balance effects are introduced by assuming that the utility function of the representative household is non-separable between consumption and real money balances. The representative final-

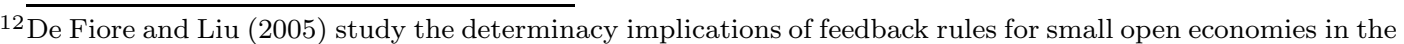
presence of transactions frictions represented by a cash-in-advance constraint. However, in stark contrast to this analysis, they do not consider the role of transactions services, the importance of domestic-price versus consumer-price inflation, nor the role of an output policy response in the feedback rule.
} 
good producer is a competitive firm that bundles domestic and imported intermediate goods into non-tradeable final goods. Intermediate-goods firms operate under monopolistic competition and set prices in a staggered fashion according to Calvo (1983). Monetary policy is governed by a Taylor-type rule where the nominal interest rate reacts to expected future inflation. In line with the recent determinacy literature, we assume that the law of one price holds, financial markets are complete, and that the degree of trade openness is proxied by the inverse of home bias in preferences for traded inputs. ${ }^{13}$ Preferences and technologies are symmetric across the two countries. We present the features of the model for the home country on the understanding that the foreign case can be analogously derived, where an asterisk denotes foreign variables.

\subsection{Final-Goods Sector}

The home final good $(Z)$ is produced by a competitive firm that uses domestic $\left(Z_{H}\right)$ and imported $\left(Z_{F}\right)$ intermediate goods as inputs according to the aggregation technology index:

$$
\begin{gathered}
Z_{t}=\left[a^{\frac{1}{\theta}} Z_{H, t}^{\frac{\theta-1}{\theta}}+(1-a)^{\frac{1}{\theta}} Z_{F, t}^{\frac{\theta-1}{\theta}}\right]^{\frac{\theta}{\theta-1}}, \\
Z_{H, t} \equiv\left[\int_{0}^{1} z_{H, t}(i)^{\frac{\varphi-1}{\varphi}} d i\right]^{\frac{\varphi}{\varphi-1}}, \quad Z_{F, t} \equiv\left[\int_{0}^{1} z_{F, t}(j)^{\frac{\varphi-1}{\varphi}} d j\right]^{\frac{\varphi}{\varphi-1}},
\end{gathered}
$$

where $z_{H}(i)$ and $z_{F}(j)$ are the respective quantities of the domestic and imported type $i$ and $j$ intermediate goods. The parameter $\theta>0$ represents the constant elasticity of substitution between aggregate home and foreign intermediate goods, $0.5<a<1$ captures the degree of home bias towards domestic intermediate goods, and $\varphi>1$ is the elasticity of substitution across individual home (foreign) intermediate goods.

Let $p_{H}(i)$ and $p_{F}(j)$ represent the respective prices of $z_{H}(i)$ and $z_{F}(j)$ in home currency. Cost minimization in final good production yields the aggregate demand conditions for home and foreign goods:

$$
Z_{H, t}=a\left(\frac{P_{H, t}}{P_{t}}\right)^{-\theta} Z_{t}, \quad Z_{F, t}=(1-a)\left(\frac{P_{F, t}}{P_{t}}\right)^{-\theta} Z_{t}
$$

${ }^{13}$ Recent empirical studies find evidence that international financial markets are incomplete and the law of one price assumption is rejected by the data (see, e.g., Rabanal and Tuesta, 2010). However, for analytical tractability and comparative purposes we adopt the standard assumptions of the existing determinacy literature. 
where the demand for individual goods is given by

$$
z_{H, t}(i)=\left(\frac{p_{H, t}(i)}{P_{H, t}}\right)^{-\varphi} Z_{H, t}, \quad z_{F, t}(j)=\left(\frac{p_{F, t}(j)}{P_{F, t}}\right)^{-\varphi} Z_{F, t} .
$$

Since the final-good producer is competitive, its price is equal to marginal cost:

$$
P_{t}=\left[a P_{H, t}^{1-\theta}+(1-a) P_{F, t}^{1-\theta}\right]^{\frac{1}{1-\theta}}
$$

where $P$ is the consumer price index and $P_{H}$ and $P_{F}$ are the respective price indices of home and foreign intermediate goods, all denominated in home currency

$$
P_{H, t} \equiv\left[\int_{0}^{1} p_{H, t}(i)^{1-\varphi} d i\right]^{\frac{1}{1-\varphi}}, \quad P_{F, t} \equiv\left[\int_{0}^{1} p_{F, t}(j)^{1-\varphi} d j\right]^{\frac{1}{1-\varphi}}
$$

We assume that there are no costs to trade between the two countries and the law of one price holds, which implies that

$$
P_{H, t}=S_{t} P_{H, t}^{*}, \quad P_{F, t}^{*}=\frac{P_{F, t}}{S_{t}}
$$

where $S$ is the nominal exchange rate. Letting $Q \equiv \frac{S P^{*}}{P}$ denote the real exchange rate, under the law of one price the CPI index (5) and its foreign equivalent imply:

$$
\left(\frac{1}{Q_{t}}\right)^{1-\theta}=\left(\frac{P_{t}}{S_{t} P_{t}^{*}}\right)^{1-\theta}=\frac{a P_{H, t}^{1-\theta}+(1-a)\left(S_{t} P_{F, t}^{*}\right)^{1-\theta}}{a\left(S_{t} P_{F, t}^{*}\right)^{1-\theta}+(1-a) P_{H, t}^{1-\theta}}
$$

Hence, with home bias between intermediate goods (i.e. $a>0.5$ ), the purchasing power parity (PPP) condition fails to hold. The relative price of foreign goods in terms of home goods, or the (home) terms of trade $T$, is defined as:

$$
T \equiv \frac{S P_{F}^{*}}{P_{H}}
$$




\subsection{Intermediate-Goods Sector}

Intermediate-sector firms hire labor $h$ to produce output given a real wage rate $w$. A firm of type $i$ has a linear production technology

$$
y_{t}(i)=h_{t}(i)
$$

and given competitive prices of labor, cost minimization yields

$$
m c_{t}=w_{t} \frac{P_{t}}{P_{H, t}}
$$

where $m c \equiv \frac{M C}{P_{H}}$ is real marginal cost. Intermediate-sector firms set prices according to Calvo (1983), where in each period there is a constant probability $1-\psi$ that a firm will be randomly selected to adjust its price, which is drawn independently of past history. A domestic firm $i$, faced with changing its price at time $t$, has to choose $p_{H, t}(i)$ to maximize its expected discounted value of profits, taking as given the indexes $P, P_{H}, P_{F}, Z$, and $Z^{*}$ :

$$
\max _{p_{H, t}(i)} E_{t} \sum_{s=0}^{\infty}(\beta \psi)^{s} X_{t, t+s}\left\{\left[p_{H, t}(i)-M C_{t+s}\right]\left[z_{H, t+s}(i)+z_{H, t+s}^{*}(i)\right]\right\}
$$

where

$$
z_{H, t+s}(i)+z_{H, t+s}^{*}(i) \equiv\left(\frac{p_{H, t}(i)}{P_{H, t+s}}\right)^{-\varphi}\left[Z_{H, t+s}+Z_{H, t+s}^{*}\right]
$$

and the firm's stochastic discount factor used to value random date $t+s$ payoffs is $\beta^{s} X_{t, t+s}=$ $\beta^{s}\left[U_{C}\left(C_{t+s}, m_{t+s}\right) / U_{C}\left(C_{t}, m_{t}\right)\right]\left(P_{t} / P_{t+s}\right)$. It follows that the optimal price-setting decision is given by:

$$
p_{H, t}(i)=\frac{\varphi}{\varphi-1} \frac{E_{t} \sum_{s=0}^{\infty}(\beta \psi)^{s} X_{t, t+s} P_{H, t+s}^{\varphi}\left(Z_{H, t+s}+Z_{H, t+s}^{*}\right) M C_{t+s}}{E_{t} \sum_{s=0}^{\infty}(\beta \psi)^{s} X_{t, t+s} P_{H, t+s}^{\varphi}\left(Z_{H, t+s}+Z_{H, t+s}^{*}\right)},
$$

where the optimal price set is a mark-up $\frac{\varphi}{\varphi-1}$ over a weighted average of expected future nominal marginal costs. 


\subsection{Representative Household}

The representative household chooses real consumption $C$, domestic real money balances $m \equiv M / P$, and labor $h$ to maximize expected discounted utility: ${ }^{14}$

$$
\max E_{0} \sum_{t=0}^{\infty} \beta^{t} U\left(C_{t}, \frac{M_{t}}{P_{t}}, h_{t}\right)
$$

where the discount factor is $0<\beta<1$, subject to the period budget constraint

$$
E_{t}\left\{\Gamma_{t, t+1} B_{t+1}\right\}+M_{t}+P_{t} C_{t} \leq B_{t}+M_{t-1}+P_{t} w_{t} h_{t}+\int_{0}^{1} \Pi_{t}(i) d(i)+\Upsilon_{t}
$$

The household carries $M_{t-1}$ units of money and $B_{t}$ units of nominal bonds into period $t$. Before proceeding to the goods market, the household visits the financial market where a state-contingent nominal bond $B_{t+1}$ can be purchased that pays one unit of domestic currency in period $t+1$ if a specific state is realized at a period $t$ price $\Gamma_{t, t+1}$. During period $t$ the household supplies labor to the intermediate-sector firms receiving real income from wages $w_{t}$, nominal profits from the ownership of domestic intermediate-sector firms $\Pi_{t}$, and a lump-sum (net) nominal transfer $\Upsilon_{t}$ from the monetary authority. The household then uses these resources to purchase the final good.

The period utility function is assumed to be non-separable between consumption and real money balances but additively separable with respect to labor: ${ }^{15}$

$$
U(C, m, h) \equiv u\left(C_{t}, m_{t}\right)-v\left(h_{t}\right)
$$

The first-order conditions from the home household's maximization problem yield:

$$
\begin{gathered}
\beta E_{t}\left\{\frac{u_{c}\left(C_{t+1}, m_{t+1}\right)}{P_{t+1}}\right\}=\frac{u_{c}\left(C_{t}, m_{t}\right)}{P_{t}} \frac{1}{R_{t}} \\
\frac{u_{m}\left(C_{t}, m_{t}\right)}{u_{c}\left(C_{t}, m_{t}\right)}=\frac{R_{t}-1}{R_{t}}
\end{gathered}
$$

\footnotetext{
14 To facilitate comparison with the vast majority of the existing literature, we adopt the traditional convention that end-of-period real money balances enter the utility function. Assuming an alternative timingassumption on money could have important consequences for equilibrium determinacy, as discussed by Carlstrom and Fuerst (2001), Kurozumi (2006), McKnight(2011b), and Stoltenberg (2012).

${ }^{15} \mathrm{As}$ is standard, we assume that $u(C, m)$ is concave and strictly increasing in each argument and both consumption and real money balances are normal goods. It is further assumed that $v(h)$, the disutility of labor supply, is an increasing, convex function.
} 


$$
\frac{v_{h}\left(h_{t}\right)}{u_{c}\left(C_{t}, m_{t}\right)}=w_{t}
$$

where $R_{t}$ denotes the gross nominal yield on a one-period discount bond defined as $R_{t}^{-1} \equiv$ $E_{t}\left\{\Gamma_{t, t+1}\right\}$. Equation (16) is the consumption Euler equation, (17) defines the money demand function, and (18) determines labor supply. Optimizing behavior further implies that the budget constraint (14) holds with equality in each period and the appropriate transversality condition is satisfied. Analogous conditions apply to the foreign household.

Letting $\left(R_{t}^{*}\right)^{-1} \equiv E_{t}\left\{\Gamma_{t, t+1} \frac{S_{t+1}}{S_{t}}\right\}$ denote the price of the state-contingent bond denominated in foreign currency, then no-arbitrage implies the following uncovered interest rate parity (UIP) condition:

$$
R_{t} E_{t}\left\{\Gamma_{t, t+1}\right\}=R_{t}^{*} E_{t}\left\{\Gamma_{t, t+1} \frac{S_{t+1}}{S_{t}}\right\}
$$

Finally, combining equation (16) with its foreign equivalent, and using the definition of the real exchange rate, the following international risk sharing condition can be obtained:

$$
Q_{t}=q_{0} \frac{u_{c^{*}}\left(C_{t}^{*}, m_{t}^{*}\right)}{u_{c}\left(C_{t}, m_{t}\right)}
$$

which follows from the assumption of complete asset markets, where the constant $q_{0} \equiv$ $Q_{0}\left[\frac{u_{c}\left(C_{0}, m_{0}\right)}{u_{c^{*}}\left(C_{0}^{*}, m_{0}^{*}\right)}\right]$.

\subsection{Monetary Authority}

Monetary policy is specified as a Taylor-type rule in which the nominal interest rate is a function of expected future inflation and current or expected future output:

$$
R_{t}=\bar{R}\left(\frac{E_{t}\left\{\pi_{t+1}^{H}\right\}}{\bar{\pi}^{H}}\right)^{\mu_{\pi}}\left(\frac{E_{t}\left\{Y_{t+k}\right\}}{\bar{Y}}\right)^{\mu_{y}}, \quad R_{t}=\bar{R}\left(\frac{E_{t}\left\{\pi_{t+1}\right\}}{\bar{\pi}}\right)^{\mu_{\pi}}\left(\frac{E_{t}\left\{Y_{t+k}\right\}}{\bar{Y}}\right)^{\mu_{y}}
$$

where $\mu_{\pi}, \mu_{y} \geq 0, k=0,1$, and $\bar{R}, \bar{Y}, \bar{\pi}^{H}$, and $\bar{\pi}$ respectively denote the steady state nominal interest rate, output, and the domestic-price, or consumer-price, inflation rate. As discussed by Hammond (2012), the vast majority of inflation-targeting central banks currently use headline consumer-price inflation as their operational target. However, Clarida et al. (2002) and Galí and Monacelli (2005) show that there are potential welfare gains from switching to 
domestic-price inflation. Hence, we consider two-versions of the Taylor rule in (21), where the monetary authority can adjust the (gross) nominal interest rate in response to expected changes in domestic-price inflation $\pi^{H}$ or in consumer-price inflation $\pi$.

Our motivation for adopting forecast-based interest rate rules of the form (21) is twofold. First, there is evidence to suggest that real economic activity is used to help forecast expected future inflation. In particular, the empirical studies of Clarida et al. (1998, 2000), Orphanides (2004), and Mihailov (2006), all find evidence that current output is used in the conduct of monetary policy for Germany, Japan, US, and UK. Second, Taylor rules of the form (21) have been shown to perform well in terms of welfare and are robust to a variety of modeling assumptions. ${ }^{16}$ For example, as shown by Clarida et al. (1999), a forecastbased interest rate rule that also responds to current output is a good approximation of the optimal policy rule for a central bank that has a quadratic loss function over inflation and output.

\subsection{Market Clearing and Equilibrium}

The home aggregate output index is defined as: $Y_{t} \equiv \int_{0}^{1} y_{t}(i) d i$. Market clearing for home intermediate-goods requires

$$
y_{t}(i)=z_{H, t}(i)+z_{H, t}^{*}(i)=\left(\frac{p_{H, t}(i)}{P_{H, t}}\right)^{-\varphi}\left[Z_{H, t}+Z_{H, t}^{*}\right]
$$

for each firm $i$. Inserting the above condition into the definition of home aggregate output yields:

$$
Y_{t}=\left[Z_{H, t}+Z_{H, t}^{*}\right] \int_{0}^{1}\left(\frac{p_{H, t}(i)}{P_{H, t}}\right)^{-\varphi}
$$

Total home demand must equal the supply of the final good

$$
Z_{t}=C_{t}
$$

and the labor market, the money market

$$
\Upsilon_{t}=M_{t}-M_{t-1},
$$

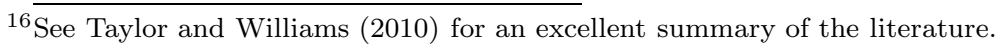


and the bond market all clear

$$
B_{t}+B_{t}^{*}=0 .
$$

Definition 1 (Rational-Expectations Equilibrium): Given an initial allocation of $B_{t_{0}}, B_{t_{0}}^{*}$, and $M_{t_{0}-1}, M_{t_{0}-1}^{*}$, a rational-expectations equilibrium is a set of sequences $\left\{C_{t}, C_{t}^{*}, M_{t}\right.$, $M_{t}^{*}, h_{t}, h_{t}^{*}, B_{t}, B_{t}^{*}, R_{t}, R_{t}^{*}, \Gamma_{t}, \Gamma_{t}^{*}, M C_{t}, M C_{t}^{*}, w_{t}, w_{t}^{*}, Y_{t}, Y_{t}^{*}, S_{t}, Q_{t}, P_{t}, P_{t}^{*}, P_{H, t}$,

$\left.P_{H, t}^{*}, P_{F, t}, P_{F, t}^{*}, Z_{t}, Z_{t}^{*}, Z_{H, t}, Z_{F, t}, Z_{H, t}^{*}, Z_{F, t}^{*}\right\}$ for all $t \geq t_{0}$ characterized by: $(i)$ the optimality conditions of the representative household, (16) to (18), the budget constraint (14) is satisfied and the transversality condition holds; (ii) cost-minimization (11) and price-setting behavior of intermediate-sector firms (13), and the aggregate version of the production function (10); (iii) the final good producer's optimality conditions, (3) and (5); (iv) all markets clear, (22) to (25); $(v)$ the monetary policy rule is satisfied (21); along with the foreign counterparts for $(i)-(v)$ and conditions (7), (8), (19), and (20).

\section{Local Equilibrium Dynamics}

\subsection{Linearized Model}

As is common in the literature, the model is log-linearized around a zero-inflation symmetric steady state. In what follows, all hatted variables denote percentage deviations from the steady state. Linearizing (16) yields the IS equation for the home country:

$$
\widehat{C}_{t}=E_{t} \widehat{C}_{t+1}-\sigma\left[\widehat{R}_{t}-E_{t} \widehat{\pi}_{t+1}+\chi\left(E_{t} \widehat{m}_{t+1}-\widehat{m}_{t}\right)\right]
$$

where $\sigma \equiv-u_{c} / u_{c c} \bar{C}>0$ is the intertemporal elasticity of substitution in consumption and $\chi \equiv \bar{m} u_{c m} / u_{c}$ is the degree of non-separability between consumption and real money balances. For analytical tractability, the ensuing analysis follows Kurozumi (2006) in imposing:

Assumption $10 \leq \chi<\left(\eta_{c} \sigma\right)^{-1} \Leftrightarrow 0 \leq 1-\eta_{c} \sigma \chi \equiv \Omega<1$,

which, as discussed in Section 3.2 below, is of most empirical relevance. 
Linearizing the price-setting equation (13) and using (6) yields the AS equation, or New Keynesian Phillips Curve (NKPC), for the home country:

$$
\widehat{\pi}_{t}^{H}=\beta E_{t} \widehat{\pi}_{t+1}^{H}+\lambda \widehat{m c}_{t}
$$

where $\lambda \equiv \frac{(1-\psi)(1-\beta \psi)}{\psi}>0$ is the real marginal cost elasticity of inflation and real marginal cost is given by:

$$
\widehat{m c}_{t}=\omega \widehat{Y}_{t}+\frac{1}{\sigma} \widehat{C}_{t}-\chi \widehat{m}_{t}+(1-a) \widehat{T}_{t}
$$

after combining the linearized versions of (5), (7), (9), (10), (11), and (18), where $\omega \equiv$ $\bar{h} v_{h h} / v_{h}>0$ is the output elasticity of real marginal cost. Domestic output follows from the linearized versions of (3), (5), their foreign equivalents, (7), (9), and the market clearing conditions (22) and (23):

$$
\widehat{Y}_{t}=2 a \theta(1-a) \widehat{T}_{t}+a \widehat{C}_{t}+(1-a) \widehat{C}_{t}^{*}
$$

Linearizing equation (17) yields the LM equation

$$
\widehat{m}_{t}=\eta_{c} \widehat{C}_{t}-\eta_{R} \widehat{R}_{t}
$$

where $\eta_{c}, \eta_{R}>0$ are the consumption elasticity and interest rate semi-elasticity of money demand, which are defined as follows:

$$
\eta_{c} \equiv \frac{\sigma^{-1}+\vartheta}{\chi+\sigma_{m}^{-1}}, \quad \eta_{R} \equiv\left(\frac{\beta}{1-\beta}\right)\left(\frac{1}{\chi+\sigma_{m}^{-1}}\right)
$$

where $\sigma_{m}^{-1} \equiv-\bar{m} u_{m m} / u_{m}, \vartheta \equiv \bar{C} u_{m c} / u_{m}$, and $\chi=s_{m} \vartheta$, where $s_{m} \equiv \bar{m} u_{m} / u_{c} \bar{C}$, with all partial derivatives evaluated at the steady state.

Linearizing equations (7), (8), (9), (19), and (20) yields expressions for the UIP condition, the terms of trade, and the consumer-price inflation differential:

$$
\begin{gathered}
\widehat{R}_{t}-\widehat{R}_{t}^{*}=E_{t} \Delta \widehat{S}_{t+1} \\
(2 a-1) \widehat{T}_{t}=\sigma^{-1}\left(\widehat{C}_{t}-\widehat{C}_{t}^{*}\right)-\chi\left(\widehat{m}_{t}-\widehat{m}_{t}^{*}\right)
\end{gathered}
$$




$$
\widehat{\pi}_{t}-\widehat{\pi}_{t}^{*}=(2 a-1)\left(\widehat{\pi}_{t}^{H}-\widehat{\pi}_{t}^{* F}\right)+2(1-a) \Delta \widehat{S}_{t}
$$

where $E_{t} \Delta \widehat{S}_{t+1} \equiv E_{t} \widehat{S}_{t+1}-\widehat{S}_{t}$ is the expected depreciation of the home currency from $t$ to $t+1$. Note that an important consequence of assuming non-separability of the utility function is that real money balances enter the IS equation (26), the AS equation (27), and the terms of trade condition (32).

The linearized equilibrium system is given by equations (26)-(30), their foreign equivalents, and equations (31)-(33), along with linearized versions of the interest rate rule (21):

$$
\widehat{R}_{t}=\mu_{\pi} E_{t} \widehat{\pi}_{t+1}^{H}+\mu_{y} E_{t} \widehat{Y}_{t+k} ; \quad \text { or } \quad \widehat{R}_{t}=\mu_{\pi} E_{t} \widehat{\pi}_{t+1}+\mu_{y} E_{t} \widehat{Y}_{t+k} ;
$$

and their foreign equivalents, where $\mu_{\pi}$ is the inflation response coefficient and $\mu_{y}$ is the output response coefficient.

It is important to stress that in the above system there are three channels of monetary policy transmission. Using (28) and (29) to eliminate $\widehat{m c}_{t}$ and $\widehat{Y}_{t}$ from (27) and combining this AS equation with its foreign equivalent and the terms of trade condition (32) generates the following expression for the domestic-price inflation differential (in deviations from the steady state):

$$
\widehat{\pi}_{t}^{H}-\widehat{\pi}_{t}^{* F}=\beta E_{t}\left(\widehat{\pi}_{t+1}^{H}-\widehat{\pi}_{t+1}^{* F}\right)+\left[\kappa_{C}+\kappa_{T} \zeta_{C}\right]\left(\widehat{C}_{t}-\widehat{C}_{t}^{*}\right)-\left[\kappa_{\mu}+\kappa_{T} \zeta_{\mu}\right]\left(\widehat{m}_{t}-\widehat{m}_{t}^{*}\right)
$$

where $\kappa_{T} \equiv 2 \lambda(1-a)[1+2 a \omega \theta]>0, \kappa_{C} \equiv \lambda[\omega(2 a-1)+1 / \sigma]>0, \zeta_{C} \equiv[\sigma(2 a-1)]^{-1}>0$, $\kappa_{\mu} \equiv \lambda \chi>0$, and $\zeta_{\mu} \equiv \chi /(2 a-1)>0$. There is the conventional aggregate demand channel, where a relative increase in the home country's interest rate lowers home consumption and reduces the domestic-price inflation differential, the sensitivity of which depends on the coefficient $\kappa_{C}$. A second transmission channel of monetary policy operates via the demand for money, which affects the cost of production of intermediate-sector firms. With real balance effects, the differential demand for money enters into (35) as a negative cost-push shock. Here an increase in the relative interest rate generates a relative reduction in the demand for domestic money, which results in an increase in real marginal cost and, given the coefficient $\kappa_{\mu}$, an increase in the domestic-price inflation differential. Finally, there is a terms of trade channel, where a relative increase in the interest rate leads to an improvement in 
Table 1: Linearized system of equations

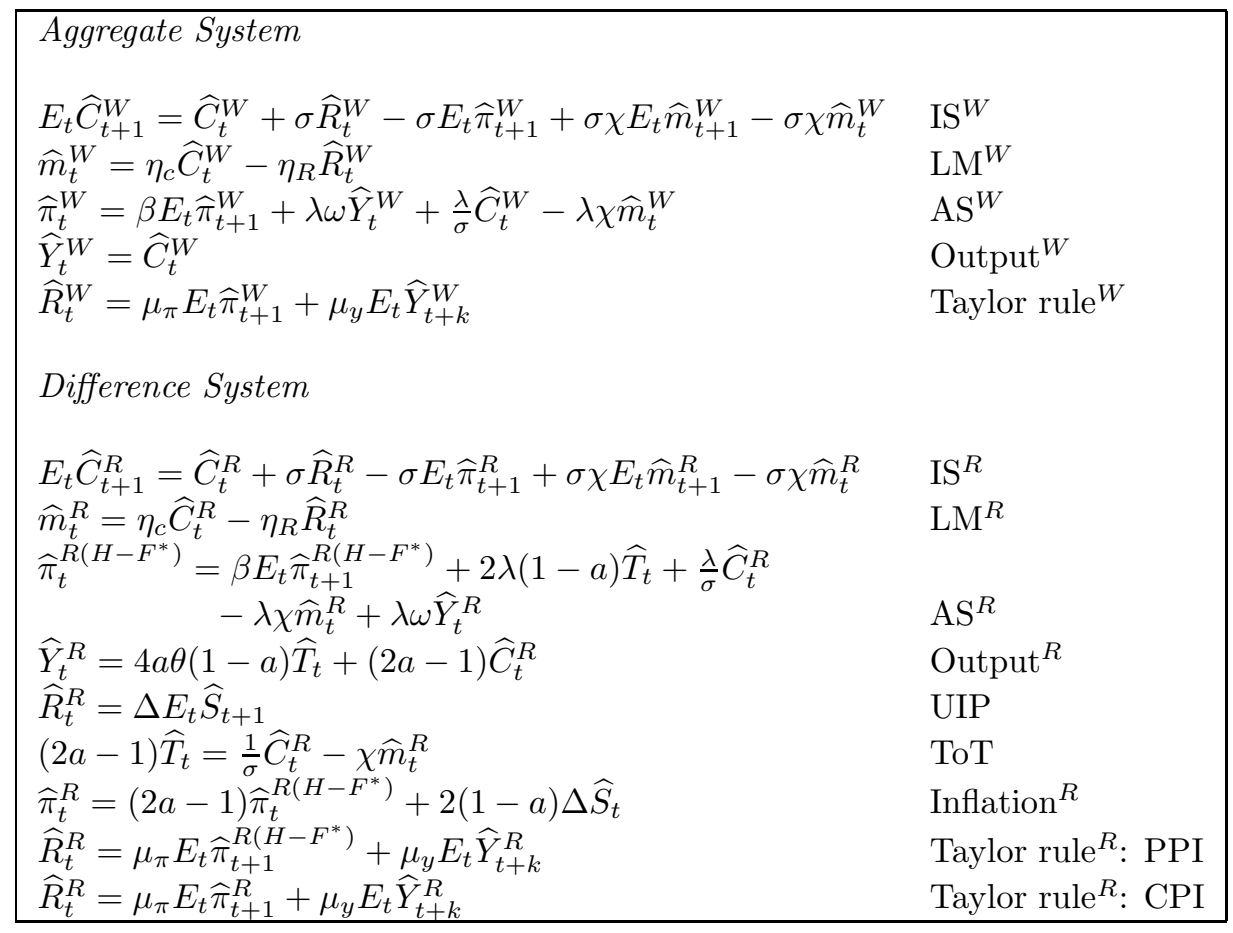

Notes: The index $W$ refers to world aggregates where $\pi^{W}=\frac{\pi+\pi^{*}}{2}=\frac{\pi^{H}+\pi^{* F}}{2}$. The index $R$ refers to the difference between home and foreign variables e.g., $\widehat{\pi}_{t}^{R\left(H-F^{*}\right)} \equiv$ $\left(\widehat{\pi}_{t}^{H}-\widehat{\pi}_{t}^{* F}\right)$.

the terms of trade, which has two separate effects on the domestic-price inflation differential. On the one hand, an improvement in the terms of trade, via an expenditure switching effect to foreign intermediate-sector goods, reduces the domestic-price inflation differential to an extent determined by $\kappa_{T} \zeta_{C}$, whereas on the other hand, it increases the inflation differential (because of real balance effects) through relative changes in real marginal cost depending on $\kappa_{T} \zeta_{\mu} \cdot{ }^{17}$

Since we are interested in obtaining analytical conditions for determinacy under both the closed and open economy dimensions of the model, it will be convenient to use the method of Aoki (1981) to split the linearized equilibrium system into two decoupled dynamic systems: the aggregate system that captures the properties of the closed world economy and the difference system that portrays the open-economy dimension. This decomposition of the linearized model into worldwide aggregates $X^{W} \equiv \frac{\widehat{X}}{2}+\frac{\widehat{X}^{*}}{2}$ and cross-country differences

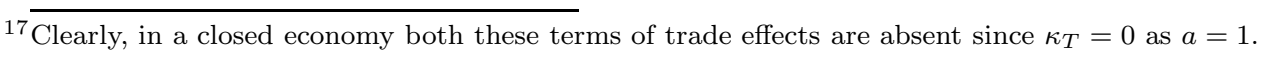


Table 2: Benchmark parameter values

$\begin{array}{lll}\beta & \text { Discount factor } & 0.99 \\ \sigma & \text { Intertemporal elasticity of substitution in consumption } & 6.4 \\ \omega & \text { Output elasticity of (real) marginal cost } & 0.47 \\ \psi & \text { Degree of price stickiness } & 0.5 \text { or } 0.75 \\ \chi & \text { Degree of non-separability of utility function } & 0 \leq \chi \leq 0.03 \\ \eta_{c} & \text { Consumption elasticity of money demand } & 1 \\ \eta_{R} & \text { Interest rate semi-elasticity of money demand } & 28 \\ \theta & \text { Elasticity of substitution between home and foreign goods } & 1 \\ 1-a & \text { Degree of trade openness } & 0.15 \text { or } 0.4\end{array}$

$X^{R} \equiv \widehat{X}-\widehat{X}^{*}$ is summarized in Table 1 . The determinacy properties of the closed-economy dimension of the model are fully characterized by the aggregate system. ${ }^{18}$ However, for the equilibrium to be determinate in the open economy it must be the case that there is a unique solution for both cross-country differences and world aggregates. ${ }^{19}$

\subsection{Parameterization}

It will be useful to illustrate our results using the benchmark values for the parameters specified in Table 2. Parameter $\beta$ is standard in the literature and $\omega$ is taken from Woodford (2003a). Consistent with the empirical estimates of Mankiw and Summers (1986), we set the consumption elasticity of money demand $\eta_{c}=1$. Following Woodford (2003a) and Kurozumi (2006), we set the interest-rate semi-elasticity of money demand $\eta_{R}=28$ and the intertemporal elasticity of substitution in consumption $\sigma=6.4$. The latter is consistent with Rotemberg and Woodford's (1997) estimate of $\sigma=6.37$ for the US economy and implies a value of the risk aversion coefficient of $1 / \sigma \approx 0.16 .^{20}$ Consistent with recent empirical estimates by Woodford (2003a), Ireland (2004), and Andrés et al. (2006), we only consider values for the degree of non-separability $0 \leq \chi \leq 0.03 .^{21}$ As noted by Benhabib

18 Note that the measure of inflation targeted in the interest-rate feedback rule is irrelevant in the aggregate system, since in a closed economy domestic and consumer-price inflation are identical concepts, i.e., $\pi^{W}=$ $\frac{\pi+\pi^{*}}{2}=\frac{\pi^{H}+\pi^{* F}}{2}$.

${ }^{19}$ Determinacy of the aggregate and difference systems implies determinacy at the individual country level since $\widehat{X}=X^{W}+\frac{X^{R}}{2}$ and $\widehat{X}^{*}=X^{W}-\frac{X^{R}}{2}$.

${ }^{20}$ Woodford (2003a) argues that a low risk aversion coefficient is justified on the grounds that the intertemporal substitution elasticity of consumption is significantly higher once investment in capital and consumer durables are considered.

${ }^{21}$ These values for $\chi$ satisfy Assumption 1 . 
and Eusepi (2005) and Huang et al. (2009), empirical estimates of $\psi$ vary considerably. We set $\psi=0.50,0.75$, which imply that prices are fixed on average for two, and four, quarters respectively. Consistent with Bergin (2006), we set $\theta=1$. Finally, for illustrative purposes, two alternative values for the degree of trade openness are also chosen, which are roughly consistent with the ratio of imports to GDP of the USA $(a=0.85)$ and Canada $(a=0.6)$.

\section{Determinacy Analysis for the Closed Economy}

This section considers the issue of local determinacy of the rational expectations equilibrium for the closed economy.

\subsection{Policy Response to Expected Future Inflation}

We first consider the determinacy implications for an interest-rate feedback rule that responds only to expected future inflation (i.e. $\mu_{y}=0$ in (34)).

Proposition 1 If the policy rule reacts only to expected future inflation, then given Assumption 1, the necessary and sufficient conditions for local equilibrium determinacy in a closed economy are:

$$
1<\mu_{\pi}<\min \left\{\Gamma_{1}^{1}, \Gamma_{3}^{1}\right\} \quad \text { or } \quad \max \left\{1, \Gamma_{1}^{1}\right\}<\mu_{\pi}<\min \left\{\Gamma_{2}^{1}, \Gamma_{3}^{1}\right\}
$$

where

$\Gamma_{1}^{1} \equiv \frac{\beta \Omega}{\eta_{R} \lambda \omega \sigma \chi} ; \quad \Gamma_{2}^{1} \equiv \frac{\Omega(1+\beta)}{\eta_{R} \lambda \omega \sigma \chi} ; \quad \Gamma_{3}^{1} \equiv \frac{2 \Omega(1+\beta)+\lambda(\Omega+\sigma \omega)}{\lambda\left[\Omega+\sigma \omega\left(1+2 \eta_{R} \chi\right)\right]}$.

Proof. See Appendix A.

Note that with separability of the utility function (i.e. $\chi=0$ ) the bounds $\Gamma_{1}^{1}$ and $\Gamma_{2}^{1}$ no

longer apply, while $\Gamma_{3}^{1}$ reduces to $\Gamma_{3, \chi=0}^{1}=1+\frac{2(1+\beta)}{\lambda(1+\sigma \omega)}$. Hence, the determinacy conditions summarized in Proposition 1 collapse to:

$$
1<\mu_{\pi}<1+\frac{2(1+\beta)}{\lambda(1+\sigma \omega)} .
$$



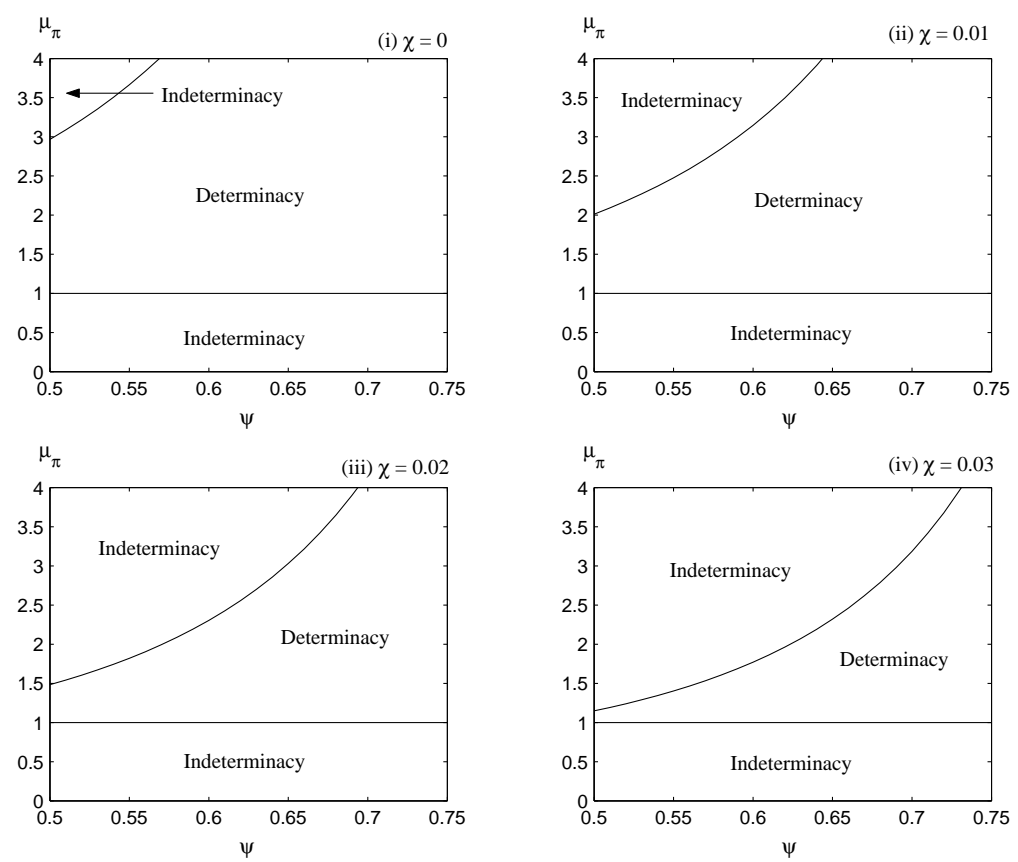

Figure 1: Determinacy region under a strict forecast-based inflation rule

It is clear from (36) and (37) that while the Taylor principle (i.e. $\mu_{\pi}>1$ ) is a necessary condition for equilibrium determinacy, it is not sufficient. The numerical analysis suggests that, with very small, empirically plausible values for $\chi$, real balance effects play a significant role in reducing the upper bound on the inflation response coefficient $\mu_{\pi}$. Using the parameter values summarized in Table 2, Figure 1 illustrates the regions of determinacy and indeterminacy for combinations of $\mu_{\pi}$ and the degree of price rigidity $\psi$ for alternative values of $\chi=0,0.01,0.02,0.03$. The top, left-hand corner of Fig. 1 shows the determinacy properties of the model under separability of the utility function. In this case, the Taylor principle easily induces determinacy of equilibrium. The other three panels of Fig. 1 show the indeterminacy implications of real balance effects as $\chi$ is increased. It is evident from Fig. 1 that real balance effects exert a destabilizing effect on the rational expectations equilibrium. By inspection, the upper bound on $\mu_{\pi}$ is tighter, the higher the degree of non-separability, and the lower the degree of price stickiness. Consequently, the Taylor principle is now weakened in its effectiveness in preventing indeterminacy. For example, setting $\chi=0.03$, then the interval of inflation response coefficients that induce determinacy is only $1<\mu_{\pi}<1.15$ with $\psi=0.50$. 
Existing studies (e.g., Kurozumi, 2006) have found that real balance effects have no implications for determinacy when the interest-rate feedback rule responds only to contemporaneous inflation. Therefore, why do real balance effects play a significant role for equilibrium determination when the interest-rate rule reacts to expected future inflation? For some intuition, first note that the relevance of real money balances arises because changes in the nominal interest rate influence real marginal cost: $\widehat{m c}_{t}^{W}=\left[\omega+1 / \sigma-\chi \eta_{c}\right] \widehat{C}_{t}^{W}+\chi \eta_{R} \widehat{R}_{t}^{W}$. Following an increase in expected future inflation, $\uparrow E_{t}\left\{\widehat{\pi}_{t+1}^{W}\right\}$, the monetary authority responds under the Taylor principle by raising the nominal and real interest rate. The increase in the nominal interest rate exerts upward pressure on $\widehat{m c}_{t}^{W}$ via the cost channel of monetary policy, whereas the corresponding rise in the real interest rate exerts downward pressure on $\widehat{m c}_{t}^{W}$ by reducing current consumption via the aggregate demand channel of monetary policy. If the cost channel is sufficiently strong then real marginal cost can rise and the initial increase in inflationary expectations can be self-fulfilling. When policy is forward-looking, $\widehat{R}_{t}^{W}=\mu_{\pi} E_{t}\left\{\widehat{\pi}_{t+1}^{W}\right\}$, then the NKPC (27) for the closed economy can be expressed as:

$$
\widehat{\pi}_{t}^{W}=\left[\beta+\lambda \chi \eta_{R} \mu_{\pi}\right] E_{t}\left\{\widehat{\pi}_{t+1}^{W}\right\}+\lambda\left[\omega+1 / \sigma-\chi \eta_{c}\right] \widehat{C}_{t}^{W}
$$

For the initial increase in inflation expectations to be self-fulfilling requires: $\uparrow \widehat{\pi}_{t}>\uparrow$ $E_{t}\left\{\widehat{\pi}_{t+1}\right\}$. This is more likely, the larger is $\chi, \lambda$ (i.e. the lower is $\psi$ ), and $\mu_{\pi}{ }^{22}$ However, under a contemporaneous feedback policy rule, $\widehat{R}_{t}^{W}=\mu_{\pi} \widehat{\pi}_{t}^{W}$, then the NKPC becomes:

$$
\widehat{\pi}_{t}^{W}=\frac{\beta}{1-\lambda \chi \eta_{R} \mu_{\pi}} E_{t}\left\{\widehat{\pi}_{t+1}^{W}\right\}+\frac{\lambda\left[\omega+1 / \sigma-\chi \eta_{c}\right]}{1-\lambda \chi \eta_{R} \mu_{\pi}} \widehat{C}_{t}^{W}
$$

By changing the parameter triplets $\left(\chi, \lambda, \mu_{\pi}\right)$ the cost channel of monetary policy cannot be strengthened without also strengthening the aggregate demand channel. Consequently, inflationary expectations cannot be made self-fulfilling and indeterminacy is not possible under the Taylor principle. ${ }^{23}$

${ }^{22}$ This cost channel is absent in models that ignore real balance effects $(\chi=0)$. As illustrated in Fig. 1, a significantly higher parameter pair $\left(\mu_{\pi}, \lambda\right)$ is consequently required to induce indeterminacy.

${ }^{23}$ In this case indeterminacy can only arise, through the aggregate demand channel of monetary policy, if the central bank follows a passive policy response, $\mu_{\pi}<1$. 


\section{$3.2 \quad$ Policy Response to Output}

We now consider the determinacy implications for the closed economy if output is also included in the interest-rate feedback rule. Proposition 2 derives the determinacy conditions when the feedback rule responds to contemporaneous output (i.e. $k=0$ in (34)) and Proposition 3 when expected future output enters the interest rate rule (i.e. $k=1$ in (34)).

\subsubsection{Policy Response to Expected Future Inflation and Contemporaneous Output}

We first examine the policy response to contemporaneous output. As previously discussed, this rule explains well how monetary policy is conducted for a number of countries.

Proposition 2 If the policy rule reacts to expected future inflation and contemporaneous output, then given Assumption 1, the necessary and sufficient conditions for local equilibrium determinacy in a closed economy are:

$$
\max \left\{0, \Gamma_{1}^{2}\right\}<\mu_{\pi}<\min \left\{\Gamma_{3}^{2}, \Gamma_{4}^{2}\right\} \quad \text { or } \quad \max \left\{0, \Gamma_{1}^{2}, \Gamma_{3}^{2}\right\}<\mu_{\pi}<\min \left\{\Gamma_{2}^{2}, \Gamma_{4}^{2}\right\}
$$

where $\Gamma_{i}^{2}, i=2,3,4$, are given in Appendix B, and

$$
\Gamma_{1}^{2} \equiv 1-\frac{\sigma\left(1-\beta-\lambda \eta_{R} \chi\right)}{\lambda(\Omega+\sigma \omega)} \mu_{y}
$$

Proof. See Appendix B.

Note that with $\chi=0$ the bounds $\Gamma_{1}^{2}$ and $\Gamma_{2}^{2}$ no longer apply and the determinacy conditions summarized in Proposition 2 collapse to:

$$
\max \left\{0,1-\frac{\sigma(1-\beta)}{\lambda(1+\sigma \omega)} \mu_{y}\right\}<\mu_{\pi}<1+\frac{2(1+\beta)}{\lambda(1+\sigma \omega)}+\frac{\sigma(1+\beta)}{\lambda(1+\sigma \omega)} \mu_{y}
$$

Now the lower and upper bounds on the inflation response coefficient $\mu_{\pi}$, given by (38) and (39), are a function of the output policy response coefficient $\mu_{y}$. For the benchmark parameter values, Figure 2 illustrates the regions of determinacy and indeterminacy for combinations of $\mu_{\pi}$ and $\mu_{y}$ under $\psi=0.75$, whereas Figure 3 considers the indeterminacy implications when a lower value for the degree of price stickiness is chosen $\psi=0.50$. The 

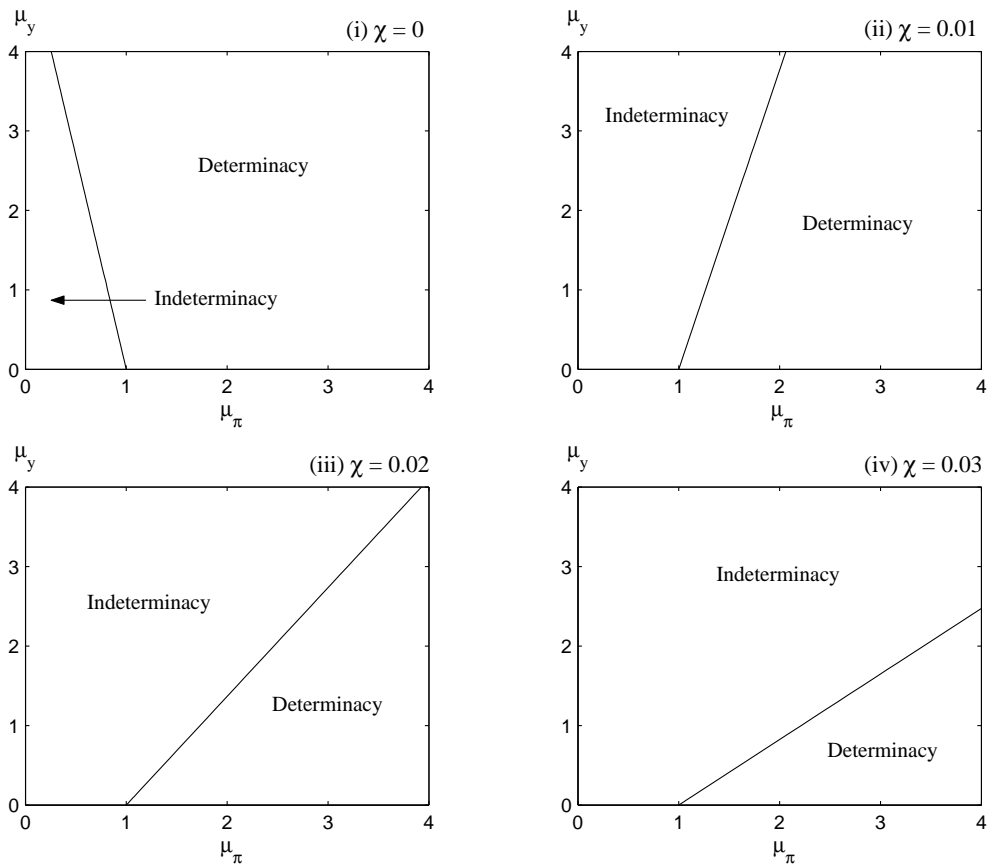

Figure 2: Determinacy region under a forecast-based inflation and contemporaneous output rule $(\psi=0.75)$
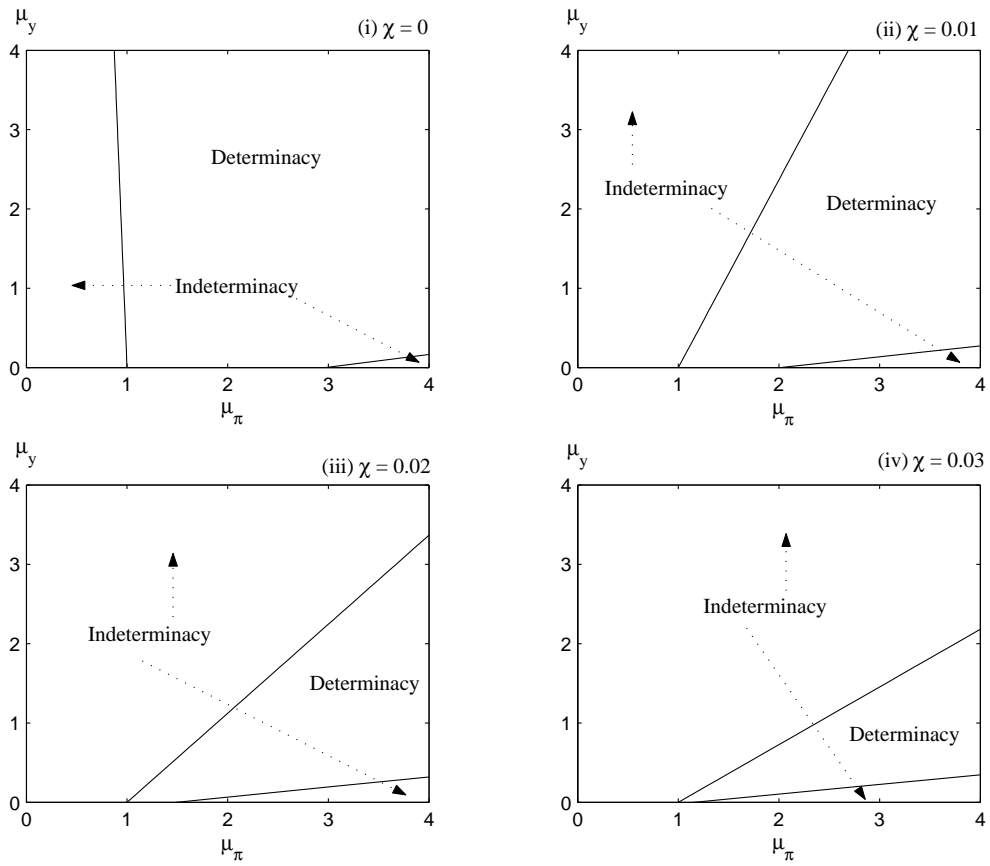

Figure 3: Determinacy region under a forecast-based inflation and contemporaneous output rule $(\psi=0.50)$ 
top, left-hand corners of Figs. 2 and 3 show the determinacy properties of the model under separability of the utility function. When $\chi=0$, the Taylor principle easily induces determinacy of equilibrium. By responding to current output, the lower bound on $\mu_{\pi}$ is reduced below unity and consequently determinacy is also attainable under a passive monetary policy (i.e. $\mu_{\pi}<1$ ). The other three panels of Figs. 2 and 3 show the indeterminacy implications of real balance effects as the extent of non-separability of the utility function is increased. The profound impact real balance effects have on the determinacy implications of the Taylor principle is evident: as $\chi$ increases, the lower bound on $\mu_{\pi}$ given in (38) pivots clockwise around the $\mu_{\pi}=1$ point. As prices become more flexible, then the upper bound on $\mu_{\pi}$ given in (38) additionally shifts anti-clockwise. From inspection of the bottom, right-hand corner of Fig. 3, the combined effect is a significant reduction in the region of determinacy.

\subsubsection{Policy Response to Expected Future Inflation and Expected Future Out- put}

For completeness, we now examine the policy response to expected future output. This specification of the interest rate rule is commonly considered in the determinacy literature (see, e.g., Bullard and Mitra, 2002; Llosa and Tuesta, 2008; Duffy and Xiao, 2011).

Proposition 3 If the policy rule reacts to expected future inflation and expected future output, then given Assumption 1, the necessary and sufficient conditions for local equilibrium determinacy in a closed economy are:

$$
\max \left\{0, \Gamma_{1}^{3}\right\}<\mu_{\pi}<\min \left\{\Gamma_{2}^{3}, \Gamma_{3}^{3}\right\}
$$

where $\Gamma_{i}^{3}, i=1,2,3$, are given in Appendix $C$.

Proof. See Appendix C.

Note that with $\chi=0$, the bound $\Gamma_{3}^{3}$ no longer applies and the determinacy conditions summarized in Proposition 3 collapse to:

$$
\max \left\{0,1-\frac{\sigma(1-\beta)}{\lambda(1+\sigma \omega)} \mu_{y}\right\}<\mu_{\pi}<1+\frac{2(1+\beta)}{\lambda(1+\sigma \omega)}-\frac{\sigma(1+\beta)}{\lambda(1+\sigma \omega)} \mu_{y}
$$



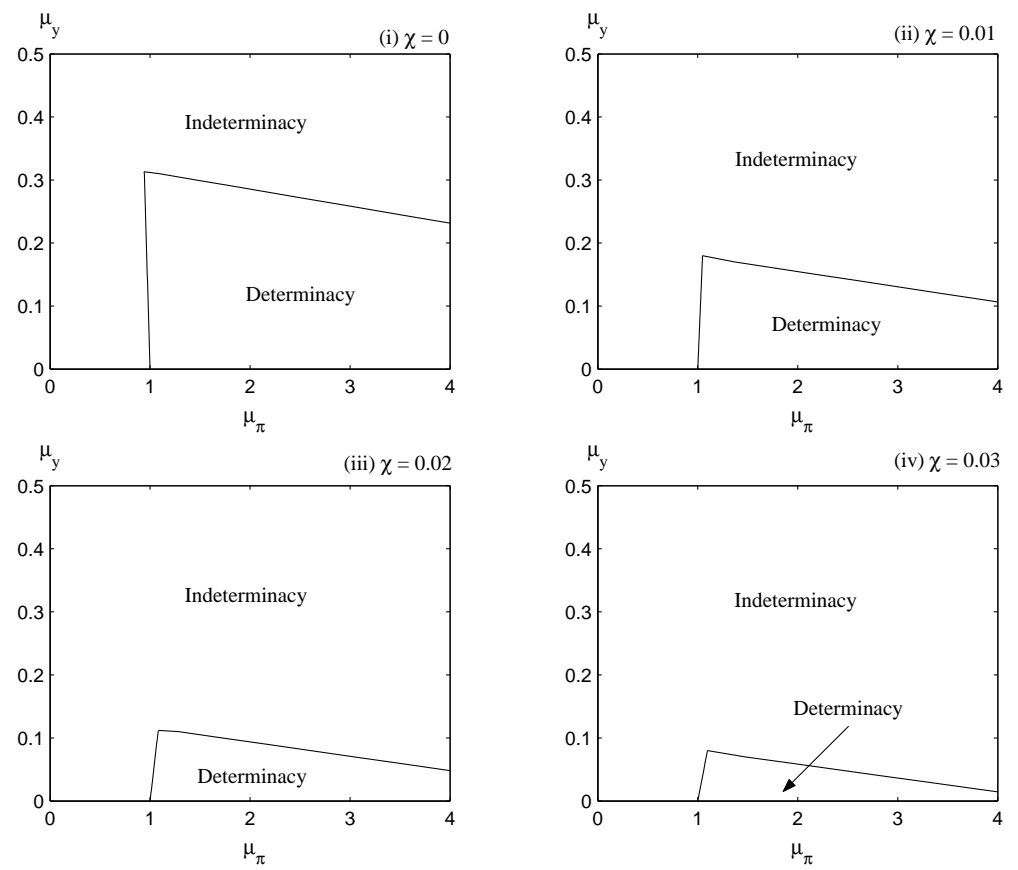

Figure 4: Determinacy region under a forecast-based inflation and output rule $(\psi=0.75)$

A policy rule that also reacts to expected future output greatly increases the range of indeterminacy under the Taylor principle. For the benchmark parameterization with $\psi=$ 0.75 , Figure 4 illustrates the regions of determinacy and indeterminacy for combinations of $\mu_{\pi}$ and $\mu_{y}$ for alternative values of $\chi=0,0.01,0.02,0.03$. The top, left-hand corner of Fig. 4 shows the determinacy properties of the model under separability of the utility function, and the other three panels show the implications for determinacy as the degree of nonseparability of the utility function is increased. By inspection of Fig. 4, indeterminacy is generated if the monetary authority is overly aggressive in its setting of the output response coefficient. Indeed, for high enough values of $\mu_{y}$ equilibrium determinacy is impossible regardless of the value of $\mu_{\pi}$. As Fig. 4 shows, not only is the upper bound on $\mu_{\pi}$ decreasing with respect to both $\chi$ and $\mu_{y}$, but in the presence of real balance effects, such a feedback rule is unlikely to render the equilibrium determinant. For instance, with $\chi=0.03$ determinacy is impossible for all $\mu_{\pi}$ if $\mu_{y} \geq 0.08$. The sensitivity analysis suggests that the region of determinacy further decreases as prices become less sticky. For example, for $\psi=0.50$ determinacy is impossible under $\chi=0.03$ if $\mu_{y} \geq 0.016$. 
What is the intuition behind these results? First note that the upper bounds $\Gamma_{i}^{2}, i=$ 2, 3, 4, given in Proposition 2 are a combination of the upper bounds $\Gamma_{j}^{1}, j=1,2,3$, given in Proposition 1 for the strict inflation forecast targeting rule, plus the additional margin now generated by also reacting to current output. This helps reduce the indeterminacy problem, since in response to a rise in the real interest rate, current output falls, which helps to offset the upward pressure on marginal cost generated via the cost channel of monetary policy. Conversely, if forward-looking output enters into the policy rule then this strengthens the cost channel by increasing the upward-pressure on expected future marginal cost making indeterminacy more likely. However, when the policy rule also reacts to either current or future output the Taylor principle is violated in the presence of real balance effects. To see this, first rearrange the lower bound given in either (39) or (41) as: $\mu_{\pi}+$ $\frac{\sigma(1-\beta)}{\lambda(1+\sigma \omega)} \mu_{y}>1$, which as discussed by Woodford (2003a) is the long-run version of the Taylor principle i.e. each percentage point of permanently higher inflation implies a permanent increase in output of $\frac{\sigma(1-\beta)}{\lambda(1+\sigma \omega)}$ percentage points. Hence, in the absence of real balance effects setting $\mu_{\pi}>1$ easily prevents indeterminacy. With real balance effects, rearranging the (empirically relevant) lower-bound $\Gamma_{1}^{2}\left(=\Gamma_{1}^{3}\right)<\mu_{\pi}$ yields: $\mu_{\pi}+\frac{\sigma\left(1-\beta-\lambda \eta_{R} \chi\right)}{\lambda(\Omega+\sigma \omega)} \mu_{y}>1$. Under the benchmark parameterization, $1-\beta-\lambda \eta_{R} \chi<0$ implying that permanently higher inflation reduces output. Thus, reacting to either current or future output in the policy rule reduces the magnitude of adjustments in the nominal interest rate to changes in inflation. Consequently, $\mu_{\pi}>1$ no longer guarantees determinacy and the monetary authority has to be more aggressive than the Taylor principle.

\section{Determinacy Analysis for Open Economies}

This section considers the issue of local determinacy of the rational expectations equilibrium for the open economy. We wish to answer the following question: Do the determinacy conditions for open economies differ from the conditions for closed economies in the presence of real balance effects? We restrict our focus to feedback rules that react to expected future (domestic or consumer-price) inflation and current output (i.e. $k=0$ in (34)), since this has most empirical relevance. 


\subsection{Reacting to Expected Domestic-Price Inflation}

Let us first consider the determinacy conditions for the open economy when the feedback rule reacts to expected future domestic-price inflation.

Proposition 4 If the policy rule reacts to expected future domestic-price inflation and contemporaneous output, then given Assumption 1, the necessary and sufficient conditions for local equilibrium determinacy in an open economy are:

$\max \left\{0, \Gamma_{1}^{2}, \Gamma_{1}^{4}\right\}<\mu_{\pi}<\min \left\{\Gamma_{3}^{2}, \Gamma_{4}^{2}, \Gamma_{3}^{4}\right\} \quad$ or $\max \left\{0, \Gamma_{1}^{2}, \Gamma_{1}^{4}, \Gamma_{3}^{2}\right\}<\mu_{\pi}<\min \left\{\Gamma_{2}^{2}, \Gamma_{2}^{4}, \Gamma_{4}^{2}, \Gamma_{3}^{4}\right\}$

where $\Gamma_{i}^{2}, i=1,2,3,4$, are defined in Proposition $2, \Gamma_{j}^{4}, j=2,3$, are given in Appendix D, and

$$
\Gamma_{1}^{4} \equiv 1-\frac{\left[(1-\beta)\left[\sigma(2 a-1)^{2}+\Omega 4 a \theta(1-a)\right]-\lambda \sigma \eta_{R} \chi(2 a-1)\right]}{\lambda \sigma \omega(2 a-1)^{2}+\Omega \lambda[1+4 a \theta \omega(1-a)]} \mu_{y} .
$$

Proof. See Appendix D.

Under domestic-price inflation targeting, whether indeterminacy is a relatively more serious problem in open economies than closed economies depends on the magnitude of the lower and upper bounds on $\mu_{\pi}$ given in (42). For the benchmark parameterization, the numerical analysis suggests that $\Gamma_{2}^{2}<\Gamma_{2}^{4}$ and $\Gamma_{4}^{2}<\Gamma_{3}^{4}$, implying that there is no change in relation to the upper bounds on $\mu_{\pi}$. Therefore, indeterminacy can only be greater in the open economy if the additional lower bound $\Gamma_{1}^{4}>\Gamma_{1}^{2}$. Figure 5 illustrates the regions of determinacy and indeterminacy under $\psi=0.75$ for combinations of $\mu_{\pi}$ and $\mu_{y}$ for a low degree of trade openness $(a=0.85)$ and a high degree of trade openness $(a=0.6) .{ }^{24}$ The top, lefthand corner of Fig. 5 shows the determinacy properties of the model under separability of the utility function, where the bold line depicts the closed economy case for comparative purposes. When $\chi=0$, increases in the degree of trade openness pivot the lower bound clockwise around the $\mu_{\pi}=1$ point, thereby increasing the range of indeterminacy. This corresponds with the standard conclusion in the open-economy literature: as the degree of openness to international trade increases, the range of indeterminacy increases (e.g. De Fiore and Liu, 2005). Consequently, the more open the economy, the greater the response

${ }^{24}$ The sensitivity analysis suggests that the following conclusions are robust to variations in the degree of price stickiness. 

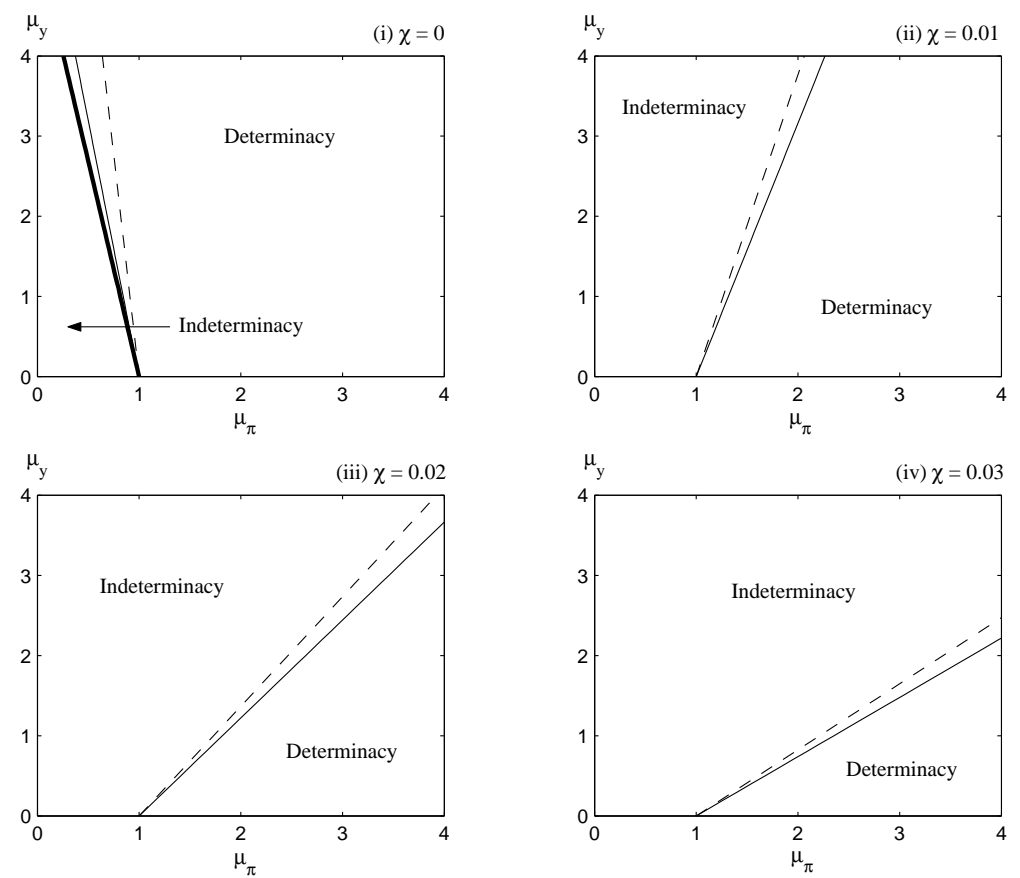

Figure 5: Determinacy region under a domestic-price inflation rule $(\psi=0.75): a=0.85$ $(-)$ vs. $a=0.6(--)$

to output is needed by the monetary authority. ${ }^{25}$ The remaining three panels of Fig. 5 show the indeterminacy implications as the degree of non-separability of the utility function is increased $\chi=0.01,0.02,0.03$. By inspection, in the presence of real balance effects, the lower bound $\Gamma_{1}^{4}$ is now decreasing with respect to the degree of trade openness. Indeed, with $a=0.6, \Gamma_{1}^{4}<\Gamma_{1}^{2}$ and thus the determinacy conditions for closed and open economies are identical. Rearranging the lower-bound $\Gamma_{1}^{4}<\mu_{\pi}$ yields:

$$
\mu_{\pi}+\frac{(1-\beta)\left[\sigma(2 a-1)^{2}+\Omega 4 a \theta(1-a)\right]-\lambda \sigma \eta_{R} \chi(2 a-1)}{\lambda \sigma \omega(2 a-1)^{2}+\Omega \lambda[1+4 a \theta \omega(1-a)]} \mu_{y}>1
$$

Since under the benchmark parameterization $(1-\beta)\left[\sigma(2 a-1)^{2}+\Omega 4 a \theta(1-a)\right]-\lambda \sigma \eta_{R} \chi(2 a-$ $1)<0$, as the degree of trade openness is increased (i.e. $\downarrow a$ ) this reduces the amount output falls in response to a permanent increase in inflation. Intuitively, when $\chi>0$ activating the cost channel of monetary policy, production spillover effects between the two countries are

${ }^{25}$ This arises because in the benchmark parameterization $\sigma>\theta$, so that home and foreign bundles are complements in the utility function, which implies positively correlated production spillover effects between the two countries following terms of trade changes. Therefore, output fluctuations result in a greater change in domestic-price inflation, as the degree of trade openness increases. 
now negatively correlated in response to terms of trade adjustments. Thus, as the degree of trade openness increases, output fluctuations result in lower changes in domestic-price inflation, thereby reducing the output response needed by the monetary authority.

\subsection{Reacting to Expected Consumer-Price Inflation}

We now consider the determinacy implications when the feedback rule reacts to expected future consumer-price inflation. As discussed earlier, there is sizable evidence that headline CPI is the actual indicator of inflation used by central banks in the setting of monetary policy (see, e.g. De Fiore and Liu, 2005; Hammond, 2012).

Proposition 5 If the policy rule reacts to expected future consumer price inflation and contemporaneous output, then given Assumption 1, the necessary and sufficient conditions for local equilibrium determinacy in an open economy are:

$$
\begin{array}{r}
\max \left\{0, \Gamma_{1}^{2}, \Gamma_{1}^{5}\right\}<\mu_{\pi}<\min \left\{\Gamma_{3}^{2}, \Gamma_{3}^{5}, \Gamma_{4}^{2}, \Gamma_{4}^{5}\right\} \quad \text { or } \\
\max \left\{0, \Gamma_{1}^{2}, \Gamma_{1}^{5}, \Gamma_{3}^{2}, \Gamma_{3}^{5}\right\}<\mu_{\pi}<\min \left\{\Gamma_{2}^{2}, \Gamma_{2}^{5}, \Gamma_{4}^{2}, \Gamma_{4}^{5}\right\}
\end{array}
$$

where $\Gamma_{i}^{2}, i=1,2,3,4$, are defined in Proposition 2 and $\Gamma_{j}^{5}, j=1,2,3,4$, are given in Appendix E.

Proof. See Appendix E.

In order to gain some further insight, we illustrate condition (43) using the benchmark parameter values summarized in Table 2. Figure 6 shows the regions of determinacy and indeterminacy for combinations of $\mu_{\pi}$ and $\mu_{y}$ for alternative values of $\chi=0,0.01,0.02,0.03$ when $a=0.85$, whereas Figure 7 considers the indeterminacy implications under a higher degree of trade openness $a=0.60$. The top, left-hand corner of Figs. 6 and 7 show the determinacy properties of the model under separability of the utility function. When $\chi=0$, and in stark contrast to the closed economy, equilibrium determinacy is no longer guaranteed under the Taylor principle. Now the upper bound on $\mu_{\pi}$ decreases as both the output response coefficient and the degree of trade openness are increased. The other three panels of Figs. 6 and 7 show the indeterminacy implications as the degree of non-separability is increased. By inspection, as $\chi$ increases, the lower bound on the inflation 

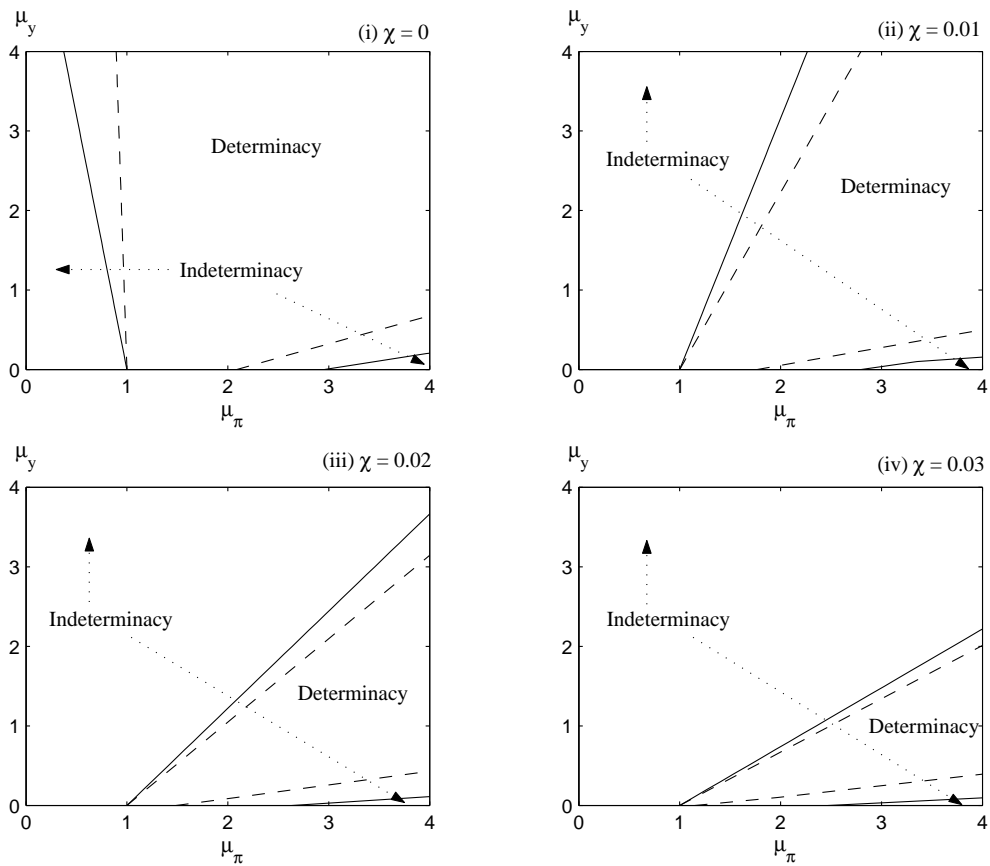

Figure 6: Determinacy region under a consumer-price inflation rule with low trade openness $(a=0.85): \psi=0.75(-)$ vs. $\psi=0.5(--)$
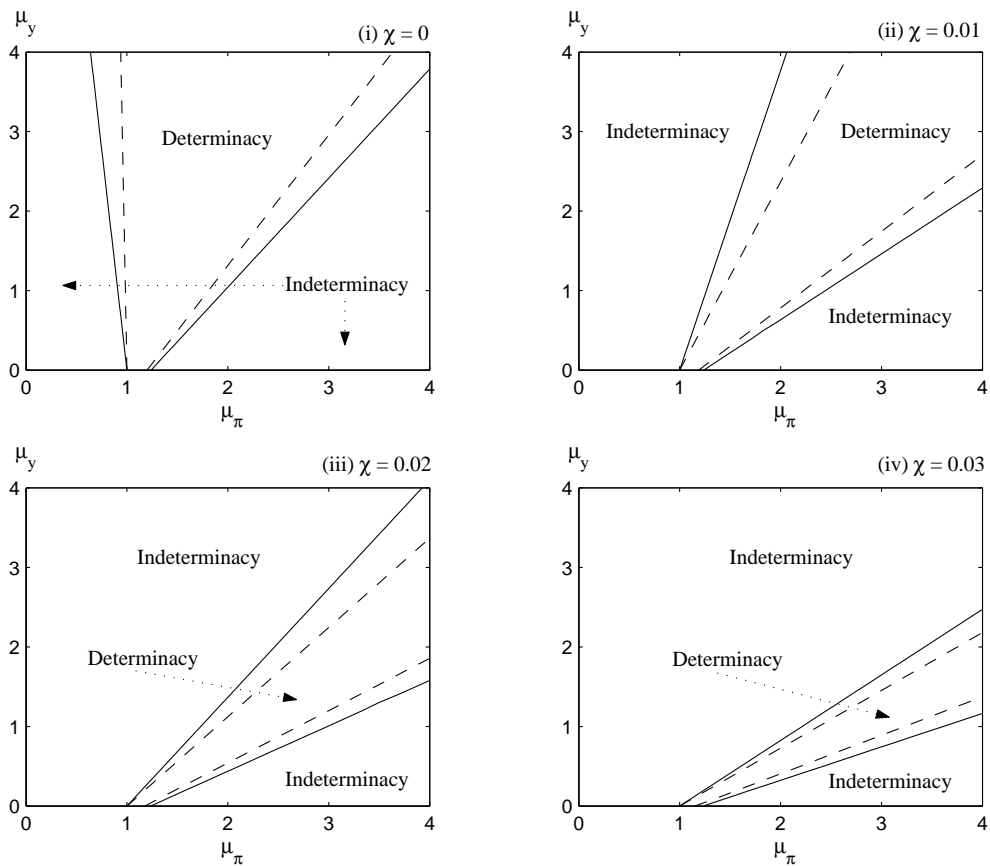

Figure 7: Determinacy region under a consumer-price inflation rule with high trade openness $(a=0.60): \psi=0.75(-)$ vs. $\psi=0.5(--)$ 
response coefficient pivots clockwise around the $\mu_{\pi}=1$ point, whereas the upper bound pivots in an anti-clockwise direction. Compared with the closed economy (see Figs. 2 and 3), the range of indeterminacy is clearly higher for open economies, and increases significantly as the degree of trade openness and non-separability of the utility function are both increased. ${ }^{26}$

To get some intuition behind this result, first note that in an open economy the expected consumer-price inflation rate depends on both the rate of expected domestic-price inflation and expected changes in the terms of trade: $E_{t}\left\{\widehat{\pi}_{t+1}^{R}\right\}=E_{t}\left\{\widehat{\pi}_{t+1}^{H-F^{*}}\right\}+2(1-$ a) $\left(E_{t}\left\{\widehat{T}_{t+1}\right\}-\widehat{T}_{t}\right)$. Since an increase in the real interest rate results in a current improvement in the terms of trade $\left(\widehat{T}_{t} \downarrow\right)$, even in the absence of real balance effects, indeterminacy can arise provided the upward pressure on consumer-price inflation, generated by the adjustments in the terms of trade, is sufficiently strong to offset the reduction in domestic-price inflation, generated via the aggregate demand channel of monetary policy. As the degree of trade openness determines the weight of influence of terms of trade adjustments on consumer-price inflation, the higher the degree of trade openness $(\downarrow a)$, the more prone is the economy to indeterminacy. With real balance effects, the indeterminacy problem is exacerbated in two ways. First, because of the cost channel of monetary policy, the downward pressure exerted on domestic-price inflation via the aggregate demand channel is lower. Secondly, the greater the degree of non-separability (i.e. $\uparrow \chi$ ), the larger the improvement in the terms of trade in response to real interest rate rises.

\subsection{Reacting to the Real Exchange Rate}

There have been recent debates in the literature on whether central banks in open economies need to additionally respond to the real exchange rate (e.g. Taylor, 2001; Kirsanova et al., 2006; Bergin et al., 2007; Benigno and Benigno, 2008). For studies that ignore the demand for money, Linnemann and Schabert (2006), Llosa and Tuesta (2008), and McKnight (2011a) have shown that indeterminacy can be reduced if the central bank places a small weight on its real exchange rate response coefficient. Following this literature, we next study

${ }^{26}$ The numerical analysis suggests that, for the baseline parameter values, the (empirically relevant) lower bound is higher in the open economy $\left(\Gamma_{1}^{2}<\Gamma_{1}^{5}\right)$ and the (empirically relevant) upper bound is lower $\left(\Gamma_{4}^{5}<\Gamma_{4}^{2}\right)$ when $a=0.85$. For a higher degree of trade openness $a=0.60$, the numerical analysis suggests that the lower bound on $\mu_{\pi}$ is the same as in the closed economy (since $\Gamma_{1}^{5}<\Gamma_{1}^{2}$ ) but the upper bound is now significantly lower $\left(\Gamma_{4}^{5}<\Gamma_{4}^{2}\right)$. 

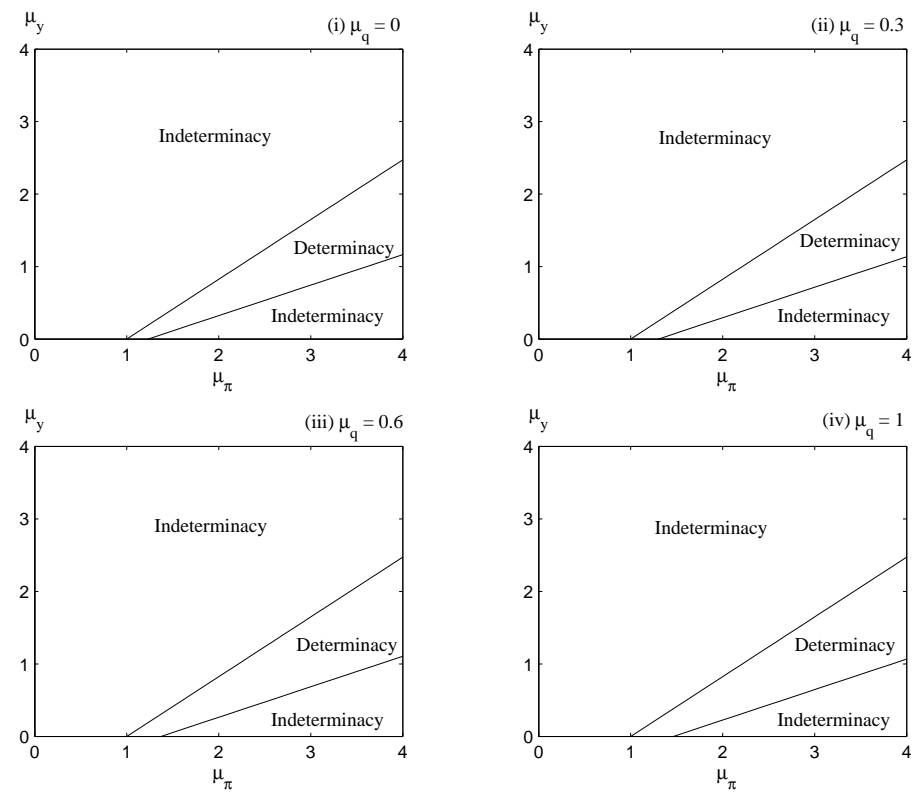

Figure 8: Determinacy region with a policy response to the real exchange rate $(a=0.60$, $\psi=0.75$, and $\chi=0.03)$

whether incorporating the real exchange rate into the policy rule can help ameliorate the indeterminacy problem previously identified with real balance effects. Consider the following log-linearized feedback rule:

$$
\widehat{R}_{t}=\mu_{\pi} E_{t} \widehat{\pi}_{t+1}+\mu_{y} \widehat{Y}_{t}+\mu_{q} \widehat{Q}_{t}
$$

where $\mu_{\pi}, \mu_{y}, \mu_{q} \geq 0 .{ }^{27}$ We simply report some numerical results for the case of (44). Figure 8 plots the regions of determinacy and indeterminacy for $a=0.6, \psi=0.75$, and $\chi=0.03$ for four values of the real exchange rate coefficient $\mu_{q}=0,0.3,0.6,1.0$. The top, left-hand corner of Fig. 8 shows the determinacy properties of the model when $\mu_{q}=0$. Fig. 8 illustrates that reacting positively to the real exchange rate has a very marginal impact on the regions of (in)determinacy. ${ }^{28}$ The numerical analysis suggests that there is only a minimal increase in the upper bound on $\mu_{\pi}$ for determinacy (and no effect on the lower bound). Even when the interest rate reacts one for one to real exchange rate movements $\left(\mu_{q}=1\right)$, the large regions of indeterminacy robustly persist in the presence of real balance

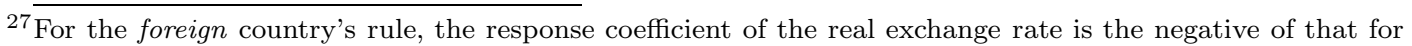
the home country.

${ }^{28}$ The sensitivity analysis indicates that this conclusion is robust to variations in $\chi, \psi$, or $a$. 
effects. Thus, the indeterminacy problems associated with real balance effects cannot be mitigated by extending the interest rate rule to include the real exchange rate.

\subsection{Ameliorating the Indeterminacy Problem}

In this subsection we offer two possible solutions to the indeterminacy problem that arises in the presence of real balance effects in both closed and open economies. It has been well-established in the determinacy literature that interest-rate rules that introduce history dependence (or inertia) via the inclusion of lagged endogenous variables can help to deliver determinacy of the rational expectations equilibrium (see, e.g., Walsh, 2003; Woodford, 2003b; Bullard and Mitra, 2007). We first introduce policy history dependence by analyzing a speed-limit rule of the type originally proposed by Walsh (2003):

$$
\widehat{R}_{t}=\mu_{\pi} E_{t} \widehat{\pi}_{t+1}+\mu_{y}\left(\widehat{Y}_{t}-\widehat{Y}_{t-1}\right)
$$

where $\mu_{\pi}, \mu_{y} \geq 0$. Now the policy rule (45) responds to the observed rate of change of output, rather than to its level as in (34). ${ }^{29}$ Figure 9 plots the regions of determinacy and indeterminacy under the benchmark parameterization for $\chi=0.03$ and $\psi=0.5$. The top panels of Fig. 9 show the determinacy properties for the closed economy, and the bottom panels depict the determinacy properties for the open economy with a degree of trade openness $a=0.6$. In both cases, we show the indeterminacy implications if the policy reacts to contemporaneous output (the left-hand side panels) and if the policy rule reacts to output growth (the right-hand side panels). By inspection, for both closed and open economies, the speed-limit policy rule rotates the lower bound on the inflation response coefficient anti-clockwise until $\mu_{\pi}=1$. This suggests that the speed-limit rule restores the Taylor principle as a necessary condition for determinacy. In terms of the upper bound on the inflation response coefficient, the speed-limit policy rule rotates the upper bound in a clockwise direction. While the upper bound can still bind for sufficiently low values of $\mu_{y}$, resulting in indeterminacy, the cost-channel of monetary policy is significantly weakened

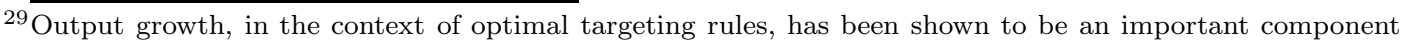
of the optimal policy. For closed economies, Giannoni and Woodford (2005) show for a variety of environments that optimal policy can be formulated as a linear relation between inflation and the change in the output gap. In an open-economy context, Benigno and Benigno (2006) find that the optimal targeting rule for cooperating policymakers also involves domestic output (gap) growth, as well as domestic-price and consumer-price inflation rates.
} 

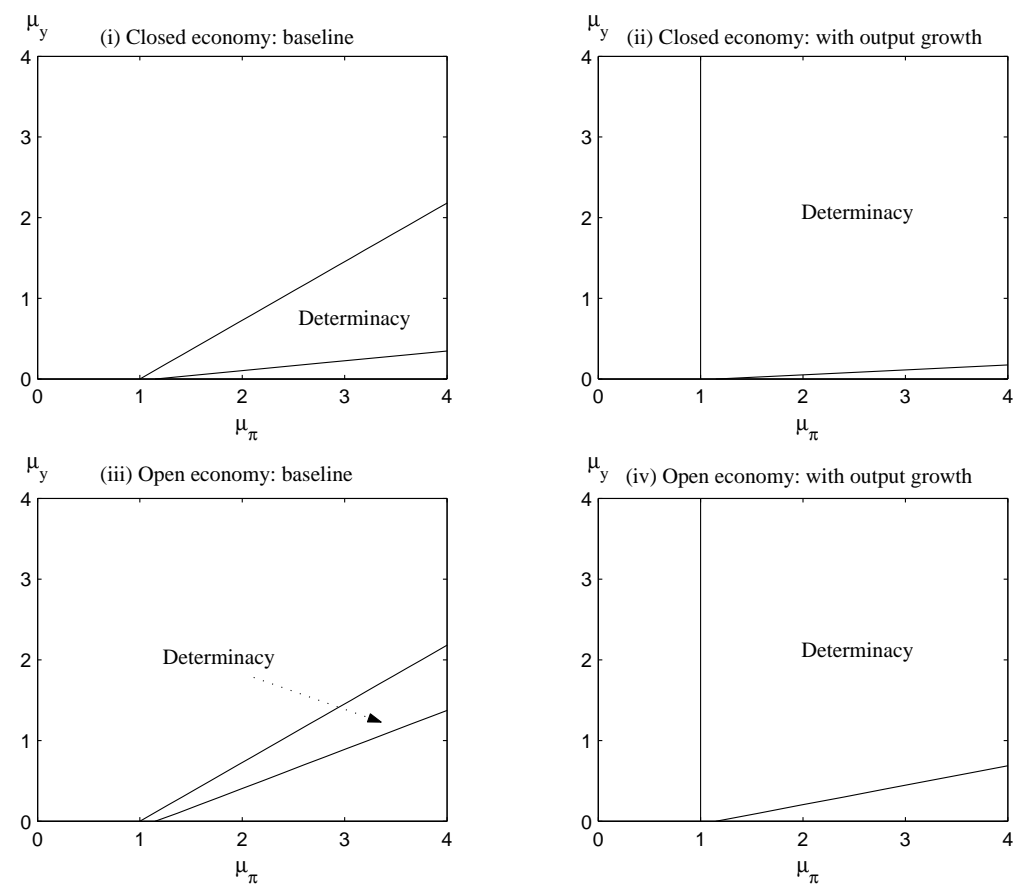

Figure 9: Determinacy region under a speed-limit rule $(\psi=0.5$ and $\chi=0.03)$
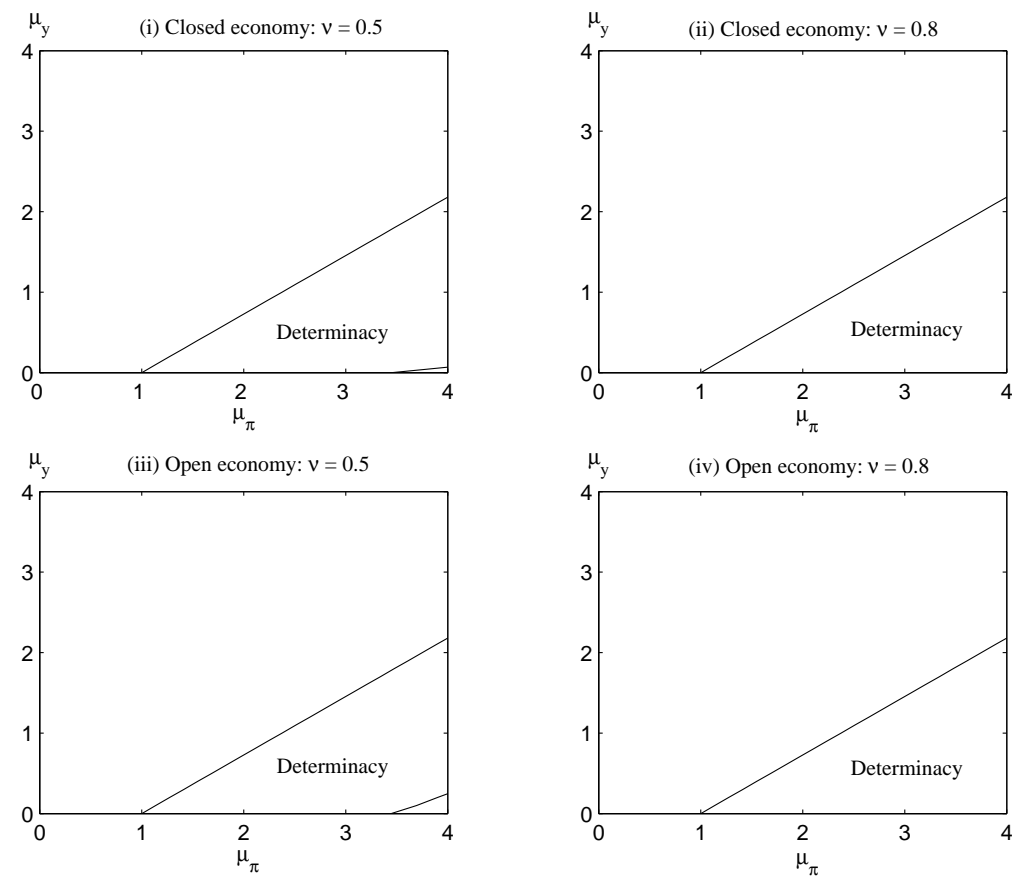

Figure 10: Determinacy region under interest-rate smoothing $(\psi=0.5$ and $\chi=0.03)$ 
with such history dependence in the policy rule. Therefore, by responding to the growth rate of output in the policy rule, the monetary authority can significantly reduce the possibility of real balance effects generating indeterminacy. Intuitively, the speed-limit rule is a potential remedy to the indeterminacy problem since the feedback from the growth rate of remedy to the indeterminacy problem since the feedback from the growth rate of output further weakens the cost channel of monetary policy. Moreover, it strengthens the magnitude of the nominal interest rate response to changes in inflation such that the Taylor principle is restored.

A policy of interest-rate smoothing can also be successful in reducing indeterminacy. For instance, consider the following instrument rule:

$$
\widehat{R}_{t}=\nu \widehat{R}_{t-1}+(1-\nu)\left(\mu_{\pi} E_{t} \widehat{\pi}_{t+1}+\mu_{y} \widehat{Y}_{t}\right)
$$

where $\nu \in(0,1)$ is the interest-rate smoothing parameter. Figure 10 plots the regions of determinacy and indeterminacy under the benchmark parameterization for $\chi=0.03$ and $\psi=0.5$ for two different empirically plausible values of $\nu=0.5,0.8$. The top panels of Fig. 10 show the determinacy properties for the closed economy, and the bottom panels depict the determinacy properties for the open economy with a degree of trade openness $a=0.6$. By inspection, interest-rate smoothing shifts the upper bound on the inflation response coefficient outwards. However, while the upper bound is increasing in $\nu$, the lower bound is not affected. ${ }^{30}$ Consequently, interest-rate smoothing is particularly effective in removing indeterminacy for low values of the output response coefficient.

\section{Conclusion}

In the conduct of monetary policy, central banks nowadays set the nominal interest rate in response to an inflation forecast. In addition, there is empirical evidence to suggest that contemporaneous output is also included in the monetary policy rule, since from a theoretical perspective it contains a useful prediction of future inflationary pressure. The existing literature has shown that the adoption of such an interest-rate rule can easily prevent indeterminacy and self-fulfilling fluctuations by implementing the Taylor principle.

\footnotetext{
${ }^{30}$ The sensitivity analysis suggests that these conclusions are robust using higher values of $\nu$.
} 
Yet, these studies have surprisingly ignored the role of money demand in their analysis. Real

balance effects generate an additional monetary transmission channel, whereby changes in money demand affect inflation via changes in real marginal cost. We have shown that small, empirically plausible real balance effects can impair sizeably, via this cost channel, the ability of the Taylor principle to induce equilibrium determinacy.

While our analysis raises some important concerns relating to the ability of central banks to avoid indeterminacy, through the implementation of commonly used interest rate rules that respond to expected future inflation, we have outlined a simple and practical solution: the introduction of policy inertia via either interest rate-smoothing or by replacing contemporaneous output with output growth. Monetary policy inertia counteracts the indeterminacy problems that arise from real balance effects helping restore the ability of the Taylor principle to prevent the emergence of self-fulfilling inflation expectations.

\section{Acknowledgments}

We are grateful to the Editor, Gianluca Benigno, and two anonymous referees for very helpful comments and suggestions, as well as to Yunus Aksoy, Philippe Bacchetta, Tatiana Damjanovic, Martin Ellison, Etienne Farvaque, Florence Huart, Thomas Lubik, Celine Poilly, Sergio Rossi, and Kenneth West. Feedback from seminar participants at the universities of Fribourg, Lausanne, Lille 1, and Reading, and from participants at the Royal Economic Society Annual Conference 2010, the COOL 3 Macroeconomics Conference 2010, and the 2011 Meeting of the European Economic Association and the Econometric Society, is also acknowledged. The usual disclaimer applies. 


\section{A Proof of Proposition 1}

The aggregate system summarized in Table 1 can be reduced to the following two-dimensional system in $\left[\widehat{m}_{t}^{W} \widehat{C}_{t}^{W}\right]^{\prime}$, where the coefficient matrix is:

$$
\mathbf{A}_{\mathbf{1}} \equiv\left[\begin{array}{cc}
\frac{\sigma\left[\lambda\left(\omega+\sigma^{-1}\right)+\frac{\beta \eta_{c}}{\eta_{R} \mu_{\pi}}\right]\left[\left(\mu_{\pi}-1\right)+\mu_{\pi} \eta_{R} \chi\right]-1}{\mu_{\pi} \eta_{R} \sigma \chi \lambda \omega-\beta \Omega} & \frac{\eta_{c}-\left[\lambda\left(\omega+\sigma^{-1}\right)+\frac{\beta \eta_{c}}{\eta_{R} \mu_{\pi}}\right]\left[\mu_{\pi} \eta_{R}+\sigma\left(\mu_{\pi}-1\right) \eta_{c}\right]}{\mu_{\pi} \eta_{R} \sigma \chi \lambda \omega-\beta \Omega} \\
\frac{\sigma\left(\lambda \chi+\frac{\beta}{\eta_{R} \mu_{\pi}}\right)\left[\left(\mu_{\pi}-1\right)+\mu_{\pi} \eta_{R} \chi\right]-\sigma \chi}{\mu_{\pi} \eta_{R} \sigma \chi \lambda \omega-\beta \Omega} & \frac{\sigma \chi \eta_{c}-\left(\lambda \chi+\frac{\beta}{\eta_{R} \mu_{\pi}}\right)\left[\mu_{\pi} \eta_{R}+\sigma\left(\mu_{\pi}-1\right) \eta_{c}\right]}{\mu_{\pi} \eta_{R} \sigma \chi \lambda \omega-\beta \Omega}
\end{array}\right] .
$$

Its determinant and trace are: $\operatorname{det} \mathbf{A}_{1}=\frac{\Omega}{\beta \Omega-\mu_{\pi} \eta_{R} \lambda \omega \sigma \chi}$ and $\operatorname{tr} \mathbf{A}_{1}=1+\frac{\left(\mu_{\pi}-1\right) \lambda(\sigma \omega+\Omega)-\Omega}{\eta_{R} \mu_{\pi} \sigma \chi \lambda \omega-\beta \Omega}$. Since $\widehat{m}^{W}$ and $\widehat{C}^{W}$ are non-predetermined variables, determinacy requires that the two eigenvalues of $\mathbf{A}_{1}$ are outside the unit circle. According to the Schur-Cohn criterion (see, e.g., LaSalle, 1986), this requires that (i) $\left|\operatorname{det} \mathbf{A}_{1}\right|>1$ and (ii) $\left|\operatorname{tr} \mathbf{A}_{1}\right|<1+\operatorname{det} \mathbf{A}_{1}$. First note that det $\mathbf{A}_{1}>1$ provided $\mu_{\pi}<\Gamma_{1}^{1}$. In this case, condition (ii) implies that $1<\mu_{\pi}<\Gamma_{3}^{1}$. Next note that $\operatorname{det} \mathbf{A}_{1}<-1$ provided $\Gamma_{1}^{1}<\mu_{\pi}<\Gamma_{2}^{1}$. Then $\left|\operatorname{tr} \mathbf{A}_{1}\right|<-1-\operatorname{det} \mathbf{A}_{1}$ implies $1<\mu_{\pi}<\Gamma_{3}^{1}$. This completes the proof.

\section{B Proof of Proposition 2}

The aggregate system summarized in Table 1 can be reduced to the following two-dimensional system in $\left[\widehat{m}_{t}^{W} \widehat{C}_{t}^{W}\right]^{\prime}$, where the coefficient matrix is:

$$
\mathbf{A}_{\mathbf{2}} \equiv\left[\begin{array}{cc}
\frac{\sigma}{\Lambda_{1}^{2}}-\frac{\Lambda_{2}^{2}}{\Lambda_{1}^{2}}\left(\frac{\sigma\left(\mu_{\pi}-1\right)}{\eta_{R} \mu_{\pi}}+\sigma \chi\right) & \frac{\Lambda_{2}^{2} \Lambda_{3}^{2}}{\Lambda_{1}^{2}}-\frac{\sigma\left(\eta_{C}-\eta_{R} \mu_{y}\right)}{\Lambda_{1}^{2}} \\
\frac{\sigma^{2} \chi}{\Lambda_{1}^{2}}-\frac{\left(\beta \sigma+\lambda \eta_{R} \sigma \chi \mu_{\pi}\right)}{\Lambda_{1}^{2}}\left(\frac{\sigma\left(\mu_{\pi}-1\right)}{\eta_{R} \mu_{\pi}}+\sigma \chi\right) & \frac{\Lambda_{3}^{2}\left(\beta \sigma+\lambda \eta_{R} \sigma \chi \mu_{\pi}\right)}{\Lambda_{1}^{2}}-\frac{\sigma^{2} \chi\left(\eta_{C}-\eta_{R} \mu_{y}\right)}{\Lambda_{1}^{2}}
\end{array}\right]
$$

with $\Lambda_{1}^{2} \equiv \beta \sigma\left(\Omega+\eta_{R} \sigma \chi \mu_{y}\right)-\lambda \eta_{R} \sigma^{2} \omega \chi \mu_{\pi}, \Lambda_{2}^{2} \equiv \beta \sigma\left(\eta_{C}-\eta_{R} \mu_{y}\right)+\lambda \eta_{R} \mu_{\pi}(1+\sigma \omega)$, $\Lambda_{3}^{2} \equiv 1+\sigma \mu_{y}+\left(\mu_{\pi}-1\right)\left(\eta_{C}-\eta_{R} \mu_{y}\right) \frac{\sigma}{\eta_{R} \mu_{\pi}}$, $\operatorname{det} \mathbf{A}_{2}=\frac{\Omega+\sigma \mu_{y}\left(1+\eta_{R} \chi\right)}{\beta \Omega+\eta_{R} \sigma \chi\left[\beta \mu_{y}-\lambda \omega \mu_{\pi}\right]}$, and $\operatorname{tr} \mathbf{A}_{2}=$ $1+\frac{\Omega-\lambda\left(\mu_{\pi}-1\right)[\Omega+\sigma \omega]+\mu_{y} \sigma\left[\eta_{R} \chi(1+\lambda)+\beta\right]}{\beta \Omega+\eta_{R} \sigma \chi\left[\beta \mu_{y}-\lambda \omega \mu_{\pi}\right]}$. Determinacy again requires that the two eigenvalues are outside the unit circle. Using the Schur-Cohn criteria, the $\operatorname{det} \mathbf{A}_{2}>1$ provided $\mu_{\pi}<\Gamma_{3}^{2}$ and in this case $\left|\operatorname{tr} \mathbf{A}_{2}\right|<1+\operatorname{det} \mathbf{A}_{2}$ implies $\max \left\{0, \Gamma_{1}^{2}\right\}<\mu_{\pi}<\Gamma_{4}^{2}$, where

$\Gamma_{3}^{2} \equiv \frac{\beta \Omega}{\lambda \sigma \omega \eta_{R} \chi}+\frac{\beta}{\lambda \omega} \mu_{y}$ 
$\Gamma_{4}^{2} \equiv \frac{2 \Omega(1+\beta)}{\lambda\left[\Omega+\sigma \omega\left(1+2 \eta_{R} \chi\right)\right]}+\frac{(\Omega+\sigma \omega)}{\left[\Omega+\sigma \omega\left(1+2 \eta_{R} \chi\right)\right]}+\frac{\sigma\left[(1+\beta)\left(1+2 \eta_{R} \chi\right)+\lambda \eta_{R} \chi\right]}{\lambda\left[\Omega+\sigma \omega\left(1+2 \eta_{R} \chi\right)\right]} \mu_{y}$.

Next note that $\operatorname{det} \mathbf{A}_{2}<-1$ provided $\Gamma_{3}^{2}<\mu_{\pi}<\Gamma_{2}^{2}$, where

$\Gamma_{2}^{2} \equiv \frac{\Omega(1+\beta)}{\lambda \sigma \omega \eta_{R} \chi}+\frac{\sigma\left[1+\eta_{R} \chi(1+\beta)\right]}{\lambda \sigma \omega \eta_{R} \chi} \mu_{y}$

Then $\left|\operatorname{tr} \mathbf{A}_{2}\right|<-1-\operatorname{det} \mathbf{A}_{2}$ implies $\max \left\{0, \Gamma_{1}^{2}\right\}<\mu_{\pi}<\Gamma_{4}^{2}$. This completes the proof.

\section{Proof of Proposition 3}

The aggregate system summarized in Table 1 can be reduced to the following three-dimensional system in $\left[\widehat{m}_{t}^{W} \widehat{C}_{t}^{W} \widehat{\pi}_{t}^{W}\right]^{\prime}$, where the coefficient matrix is:

$$
\mathbf{A}_{\mathbf{3}} \equiv\left[\begin{array}{ccc}
1+\frac{\lambda\left(\sigma \mu_{y}-\mu_{\pi}\right)}{\beta \sigma \mu_{y}}-\frac{1-\sigma \mu_{y}}{\eta_{R} \sigma \chi \mu_{y}} & \frac{\eta_{C}\left(1-\sigma \mu_{y}\right)}{\eta_{R} \sigma \chi \mu_{y}}-\frac{1}{\sigma \chi}-\frac{\lambda(1+\sigma \omega)\left(\sigma \mu_{y}-\mu_{\pi}\right)}{\beta \sigma^{2} \chi \mu_{y}} & \frac{\sigma \mu_{y}-\mu_{\pi}}{\beta \sigma \chi \mu_{y}} \\
-\frac{1}{\eta_{R} \mu_{y}}-\frac{\lambda \chi \mu_{\pi}}{\beta \mu_{y}} & \frac{\eta_{C}}{\eta_{R} \mu_{y}}+\frac{\lambda \mu_{\pi}(1+\sigma \omega)}{\beta \sigma \mu_{y}} & -\frac{\mu_{\pi}}{\beta \mu_{y}} \\
\frac{\lambda \chi}{\beta} & -\frac{\lambda(1+\sigma \omega)}{\beta \sigma} & \frac{1}{\beta}
\end{array}\right]
$$

The three eigenvalues of $\mathbf{A}_{3}$ are solutions to the cubic equation $r^{3}+a_{2} r^{2}+a_{1} r+a_{0}=0$, where

$$
\begin{array}{r}
a_{2}=-1-\frac{1}{\beta}-\frac{\lambda\left(\omega \mu_{\pi}+\mu_{y}\right)}{\beta \mu_{y}}-\frac{1}{\chi \eta_{R}}+\frac{\Omega}{\eta_{R} \sigma \chi \mu_{y}} \\
a_{1}=\frac{1}{\beta}+\frac{\lambda\left(\mu_{\pi}-1\right)(\Omega+\sigma \omega)}{\beta \eta_{R} \sigma \chi \mu_{y}}+\frac{1}{\beta \eta_{R} \chi}+\frac{\lambda \omega \mu_{\pi}}{\beta \mu_{y}}-\frac{(1+\beta) \Omega}{\beta \eta_{R} \sigma \chi \mu_{y}} \\
a_{0}=\frac{\Omega}{\beta \eta_{R} \sigma \chi \mu_{y}} .
\end{array}
$$

As there are no predetermined variables, determinacy requires that all the eigenvalues are outside the unit circle. Since $a_{0}>0$, this is the case if and only if the following Schur-Cohn criterion is satisfied: (i) $1+a_{2}+a_{1}+a_{0}>0$, (ii) $-1+a_{2}-a_{1}+a_{0}>0$, and (iii) $a_{0}^{2}-1>\mid a_{0} a_{2}-$ $a_{1} \mid$. Conditions (i) and (ii) simplify respectively to $\lambda\left(\mu_{\pi}-1\right)(\Omega+\sigma \omega)+\sigma \mu_{y}\left(1-\beta-\lambda \eta_{R} \chi\right)>$ 0 , and $2 \Omega(1+\beta)+\lambda(\Omega+\sigma \omega)>\lambda \mu_{\pi}\left[\Omega+\sigma \omega\left(1+2 \eta_{R} \chi\right)\right]+\sigma \mu_{y}\left[1+\beta+\eta_{R} \chi(\lambda+2(1+\beta))\right]$, which imply $\max \left\{0, \Gamma_{1}^{3}\right\}<\mu_{\pi}<\Gamma_{2}^{3}$, where

$\Gamma_{1}^{3} \equiv 1-\frac{\sigma\left(1-\beta-\lambda \eta_{R} \chi\right)}{\lambda(\Omega+\sigma \omega)} \mu_{y}, \quad \Gamma_{2}^{3} \equiv \frac{2 \Omega(1+\beta)+\lambda(\Omega+\sigma \omega)}{\lambda\left[\Omega+\sigma \omega\left(1+2 \eta_{R} \chi\right)\right]}-\frac{\sigma\left[(1+\beta)\left(1+2 \eta_{R} \chi\right)+\lambda \eta_{R} \chi\right]}{\lambda\left[\Omega+\sigma \omega\left(1+2 \eta_{R} \chi\right)\right]} \mu_{y}$. 
For condition (iii), the case $1-a_{0}^{2}<a_{0} a_{2}-a_{1}$ implies $\mu_{\pi}<\Gamma_{3}^{3}$, where

$$
\begin{gathered}
\Gamma_{3}^{3} \equiv \frac{\Omega^{2}(1+\beta)}{\beta \lambda \eta_{R} \chi \sigma \mu_{y}\left[\Omega\left(1+\frac{\omega}{\beta \mu_{y}}\right)+\sigma \omega\left(1+\eta_{R} \chi\right)\right]}-\frac{\Omega\left[(1-\beta)(1+\lambda+\beta)+\frac{\beta}{\eta_{R} \chi}\right]}{\beta \lambda\left[\Omega\left(1+\frac{\omega}{\beta \mu_{y}}\right)+\sigma \omega\left(1+\eta_{R} \chi\right)\right]} \\
+\frac{\sigma \omega}{\Omega\left(1+\frac{\omega}{\beta \mu_{y}}\right)+\sigma \omega\left(1+\eta_{R} \chi\right)}-\frac{\sigma\left[1+\eta_{R} \chi(1+\beta)\right]}{\lambda\left[\Omega\left(1+\frac{\omega}{\beta \mu_{y}}\right)+\sigma \omega\left(1+\eta_{R} \chi\right)\right]} \mu_{y} .
\end{gathered}
$$

For the case $a_{0}^{2}-1>a_{0} a_{2}-a_{1}$, this can be expressed as:

$$
\begin{array}{r}
\frac{\Omega}{\beta}\left[\frac{\Omega(1-\beta)}{\eta_{R} \sigma \chi \mu_{y}}+(1-\beta)(1+\beta+\lambda)+\frac{\lambda \omega \mu_{\pi}}{\mu_{y}}+\frac{\beta}{\eta_{R} \chi}\right]+(1-\beta) \eta_{R} \sigma \chi \mu_{y}+\lambda \eta_{R} \sigma \omega \chi \mu_{\pi}+\lambda \Omega \\
+\beta \sigma \mu_{y}+\eta_{R} \lambda \sigma \chi \mu_{y}+\left[\lambda\left(\mu_{\pi}-1\right)(\Omega+\sigma \omega)+\sigma \mu_{y}\left(1-\beta-\lambda \eta_{R} \chi\right)\right]>0
\end{array}
$$

which, by inspection, is always satisfied if condition (i) holds. This completes the proof.

\section{Proof of Proposition 4}

The difference system summarized in Table 1 can be reduced to the following two-dimensional system in $\left[\widehat{m}_{t}^{R} \widehat{C}_{t}^{R}\right]^{\prime}$, where the coefficient matrix is:

$$
\mathbf{B} \equiv\left[\begin{array}{cc}
\frac{\sigma \Lambda_{1}^{4} \Lambda_{2}^{4}+\Lambda_{3}^{4}}{\eta_{R} \sigma \chi(2 a-1)\left[\lambda \omega \mu_{\pi}-\beta \mu_{y}\right]-\beta \Omega} & \frac{\Lambda_{5}^{4}-\Lambda_{1}^{4} \Lambda_{4}^{4}}{\eta_{R} \sigma \chi(2 a-1)\left[\lambda \omega \mu_{\pi}-\beta \mu_{y}\right]-\beta \Omega} \\
\frac{\sigma \Lambda_{2}^{4} \Lambda_{6}^{4}+\sigma \chi \Lambda_{3}^{4}}{\eta_{R} \sigma \chi(2 a-1)\left[\lambda \omega \mu_{\pi}-\beta \mu_{y}\right]-\beta \Omega} & \frac{\sigma \chi \Lambda_{5}^{4}-\Lambda_{4}^{4} \Lambda_{6}^{4}}{\eta_{R} \sigma \chi(2 a-1)\left[\lambda \omega \mu_{\pi}-\beta \mu_{y}\right]-\beta \Omega}
\end{array}\right],
$$

with $\Lambda_{1}^{4} \equiv \beta \eta_{c}-\frac{\beta \eta_{R} \mu_{y}}{\sigma(2 a-1)}\left[4 a \theta(1-a)+\sigma(2 a-1)^{2}\right]+\frac{\lambda \eta_{R} \mu_{\pi}}{\sigma(2 a-1)}\left[1+\sigma \omega(2 a-1)^{2}+4 a \theta \omega(1-a)\right]$, $\Lambda_{2}^{4} \equiv \chi+\frac{(2 a-1)\left(\mu_{\pi}-1\right)}{\eta_{R} \mu_{\pi}}+\frac{\mu_{y} 4 a \theta \chi(1-a)}{\mu_{\pi}}, \Lambda_{3}^{4} \equiv \frac{\eta_{R} \mu_{y} 4 a \theta \chi(1-a)}{2 a-1}-1, \Lambda_{4}^{4} \equiv 1+\frac{\sigma \eta_{c}(2 a-1)\left(\mu_{\pi}-1\right)}{\eta_{R} \mu_{\pi}}+$ $\frac{\mu_{y}}{\mu_{\pi}}\left[4 a \theta(1-a)+\sigma(2 a-1)^{2}\right], \Lambda_{5}^{4} \equiv \eta_{c}-\frac{\eta_{R} \mu_{y}}{\sigma(2 a-1)}\left[4 a \theta(1-a)+\sigma(2 a-1)^{2}\right], \Lambda_{6}^{4} \equiv \beta-\frac{\beta \eta_{R} \mu_{y} 4 a \theta \chi(1-a)}{2 a-1}+$ $\frac{\lambda \chi \eta_{R} \mu_{\pi}}{2 a-1}[1+4 a \theta \omega(1-a)], \operatorname{det} \mathbf{B}=\frac{\Omega\left[1+\mu_{y} 4 a \theta(1-a)\right]+\mu_{y} \sigma(2 a-1)\left[(2 a-1)+\chi \eta_{R}\right]}{\beta \Omega+(2 a-1) \chi \sigma \eta_{R}\left[\beta \mu_{y}-\lambda \omega \mu_{\pi}\right]}$, and $\operatorname{tr} \mathbf{B}=1+$ $\frac{\Omega-\lambda\left(\mu_{\pi}-1\right)\left[\sigma \omega(2 a-1)^{2}+\Omega[1+4 a \theta \omega(1-a)]\right]}{\beta \Omega-(2 a-1) \chi \sigma \eta_{R}\left[\lambda \omega \mu_{\pi}-\beta \mu_{y}\right]}+\frac{\mu_{y}\left[\sigma \eta_{R} \chi(2 a-1)(1+\lambda)+\sigma \beta(2 a-1)^{2}+\beta \Omega 4 a \theta(1-a)\right]}{\beta \Omega-(2 a-1) \chi \sigma \eta_{R}\left[\lambda \omega \mu_{\pi}-\beta \mu_{y}\right]}$. Determinacy again requires that the two eigenvalues are outside the unit circle. Using the SchurCohn conditions, $\operatorname{det} \mathbf{B}>1$ provided $\mu_{\pi}<\frac{\beta \Omega+(2 a-1) \beta \chi \eta_{R} \sigma \mu_{y}}{\eta_{R} \chi \sigma \omega \lambda(2 a-1)} \equiv \Gamma_{4}^{4}$ and in this case 
$|\operatorname{tr} \mathbf{B}|<1+\operatorname{det} \mathbf{B}$ implies $\max \left\{0, \Gamma_{1}^{4}\right\}<\mu_{\pi}<\Gamma_{3}^{4}$, where

$$
\begin{aligned}
& \Gamma_{3}^{4} \equiv \frac{2 \Omega(1+\beta)+\lambda \sigma \omega(2 a-1)^{2}+\lambda \Omega[1+4 a \theta \omega(1-a)]}{\lambda \Omega[1+4 a \theta \omega(1-a)]+\lambda \sigma \omega(2 a-1)\left[2 a-1+2 \eta_{R} \chi\right]} \\
& +\frac{\left[(1+\beta)\left[\Omega 4 a \theta(1-a)+\sigma(2 a-1)^{2}\right]+\sigma \eta_{R} \chi(2 a-1)[\lambda+2(1+\beta)]\right]}{\lambda \Omega[1+4 a \theta \omega(1-a)]+\lambda \sigma \omega(2 a-1)\left[2 a-1+2 \eta_{R} \chi\right]} \mu_{y} .
\end{aligned}
$$

Next note that $\operatorname{det} \mathbf{B}<-1$ provided $\Gamma_{4}^{4}<\mu_{\pi}<\Gamma_{2}^{4}$, where

$\Gamma_{2}^{4} \equiv \frac{\Omega(1+\beta)}{\lambda \sigma \omega \eta_{R} \chi(2 a-1)}+\frac{\left[\sigma(2 a-1)^{2}+\Omega 4 a \theta(1-a)+(2 a-1) \sigma \eta_{R} \chi(1+\beta)\right]}{(2 a-1) \lambda \sigma \omega \eta_{R} \chi} \mu_{y}$.

Then $|\operatorname{tr} \mathbf{B}|<-1-\operatorname{det} \mathbf{B}$ implies $\Gamma_{1}^{4}<\mu_{\pi}<\Gamma_{3}^{4}$. Therefore, $\max \left\{0, \Gamma_{1}^{4}\right\}<\mu_{\pi}<\Gamma_{3}^{4}$, and either $\mu_{\pi}<\Gamma_{4}^{4}$ or $\Gamma_{4}^{4}<\mu_{\pi}<\Gamma_{2}^{4}$, are the necessary and sufficient conditions for the difference system. Comparing these bounds on $\mu_{\pi}$ with the determinacy conditions obtained for the aggregate system given in Proposition 2, it is straightforward to verify that $\Gamma_{1}^{2} \lessgtr \Gamma_{1}^{4}$, $\Gamma_{2}^{2} \lessgtr \Gamma_{2}^{4}, \Gamma_{3}^{2}<\Gamma_{4}^{4}$, and $\Gamma_{4}^{2} \lessgtr \Gamma_{3}^{4}$. This completes the proof.

\section{E Proof of Proposition 5}

The difference system summarized in Table 1 can be reduced to the following two-dimensional system in $\left[\widehat{m}_{t}^{R} \widehat{C}_{t}^{R}\right]^{\prime}$, where the coefficient matrix is:

$\mathbf{C} \equiv\left[\begin{array}{cc}\frac{-\sigma \Lambda_{1}^{5} \Lambda_{2}^{5}-\Lambda_{3}^{5}}{\beta \Omega\left[1-2(1-a) \mu_{\pi}\right]-\eta_{R} \sigma \chi(2 a-1)\left[\lambda \omega \mu_{\pi}(2 a-1)-\beta \mu_{y}\right]} & \frac{\Lambda_{1}^{5} \Lambda_{4}^{5}-\Lambda_{5}^{5}}{\beta \Omega\left[1-2(1-a) \mu_{\pi}\right]-\eta_{R} \sigma \chi(2 a-1)\left[\lambda \omega \mu_{\pi}(2 a-1)-\beta \mu_{y}\right]} \\ \frac{-\sigma \Lambda_{2}^{5} \Lambda_{6}^{5}-\sigma \chi \Lambda_{3}^{5}}{\beta \Omega\left[1-2(1-a) \mu_{\pi}\right]-\eta_{R} \sigma \chi(2 a-1)\left[\lambda \omega \mu_{\pi}(2 a-1)-\beta \mu_{y}\right]} & \frac{\Lambda_{4}^{5} \Lambda_{6}^{5}-\sigma \chi \Lambda_{5}^{5}}{\beta \Omega\left[1-2(1-a) \mu_{\pi}\right]-\eta_{R} \sigma \chi(2 a-1)\left[\lambda \omega \mu_{\pi}(2 a-1)-\beta \mu_{y}\right]}\end{array}\right]$,

with $\Lambda_{1}^{5} \equiv \beta \eta_{c}\left[1-2(1-a) \mu_{\pi}\right]-\frac{\beta \eta_{R} \mu_{y}}{\sigma(2 a-1)}\left[4 a \theta(1-a)+\sigma(2 a-1)^{2}\right]+\frac{\lambda \eta_{R} \mu_{\pi}}{\sigma}\left[1+\sigma \omega(2 a-1)^{2}+4 a \theta \omega(1-a)\right]$, $\Lambda_{2}^{5} \equiv \chi+\frac{\left(\mu_{\pi}-1\right)}{\eta_{R} \mu_{\pi}}+\frac{\mu_{y} 4 a \theta \chi(1-a)}{\mu_{\pi}(2 a-1)}, \Lambda_{3}^{5} \equiv \frac{\eta_{R} \mu_{y} 4 a \theta \chi(1-a)}{2 a-1}-\left[1-2(1-a) \mu_{\pi}\right], \Lambda_{4}^{5} \equiv 1+\frac{\sigma \eta_{c}\left(\mu_{\pi}-1\right)}{\eta_{R} \mu_{\pi}}+$ $\frac{\mu_{y}}{\mu_{\pi}(2 a-1)}\left[4 a \theta(1-a)+\sigma(2 a-1)^{2}\right], \Lambda_{5}^{5} \equiv \eta_{c}\left[1-2(1-a) \mu_{\pi}\right]-\frac{\eta_{R} \mu_{y}}{\sigma(2 a-1)}\left[4 a \theta(1-a)+\sigma(2 a-1)^{2}\right]$, $\Lambda_{6}^{5} \equiv \beta\left[1-2(1-a) \mu_{\pi}\right]-\frac{\beta \eta_{R} \mu_{y} 4 a \theta \chi(1-a)}{2 a-1}+\lambda \chi \eta_{R} \mu_{\pi}[1+4 a \theta \omega(1-a)]$, $\operatorname{det} \mathbf{C}=\frac{\Omega\left[1-2(1-a) \mu_{\pi}\right]+\mu_{y}\left[4 a \theta(1-a) \Omega+(2 a-1) \chi \eta_{R} \sigma+\sigma(2 a-1)^{2}\right]}{\beta \Omega\left[1-2(1-a) \mu_{\pi}\right]-\eta_{R} \sigma \chi(2 a-1)\left[\lambda \omega \mu_{\pi}(2 a-1)-\beta \mu_{y}\right]}$, and $\operatorname{tr} \mathbf{C}=1+\frac{\Omega\left[1-2(1-a) \mu_{\pi}\right]-\lambda\left(\mu_{\pi}-1\right)\left[\sigma \omega(2 a-1)^{2}+\Omega[1+4 a \theta \omega(1-a)]\right]}{\beta \Omega\left[1-2(1-a) \mu_{\pi}\right]-\eta_{R} \sigma \chi(2 a-1)\left[\lambda \omega \mu_{\pi}(2 a-1)-\beta \mu_{y}\right]}+\frac{\mu_{y}\left[\sigma \eta_{R} \chi(2 a-1)(1+\lambda)+\sigma \beta(2 a-1)^{2}+\beta \Omega 4 a \theta(1-a)\right]}{\beta \Omega\left[1-2(1-a) \mu_{\pi}\right]-\eta_{R} \sigma \chi(2 a-1)\left[\lambda \omega \mu_{\pi}(2 a-1)-\beta \mu_{y}\right]}$.

Determinacy again requires that the two eigenvalues are outside the unit circle. Using the Schur-Cohn conditions, $\operatorname{det} \mathbf{C}>1$ provided $\mu_{\pi}<\Gamma_{3}^{5}$ and in this case $|\operatorname{tr} \mathbf{C}|<1+\operatorname{det} \mathbf{C}$ 
implies $\max \left\{0, \Gamma_{1}^{5}\right\}<\mu_{\pi}<\Gamma_{4}^{5}$, where

$$
\begin{aligned}
& \Gamma_{1}^{5} \equiv 1-\frac{\left[(1-\beta)\left[\sigma(2 a-1)^{2}+\Omega 4 a \theta(1-a)\right]-\lambda \sigma \eta_{R} \chi(2 a-1)\right]}{\lambda \sigma \omega(2 a-1)^{2}+\Omega \lambda[1+4 a \theta \omega(1-a)]} \mu_{y}, \\
& \Gamma_{3}^{5} \equiv \frac{\beta \Omega+\beta \sigma \eta_{R} \chi(2 a-1) \mu_{y}}{2 \beta \Omega(1-a)+\lambda \sigma \omega \eta_{R} \chi(2 a-1)^{2}}, \\
& \Gamma_{4}^{5} \equiv \frac{2 \Omega(1+\beta)+\lambda \sigma \omega(2 a-1)^{2}+\lambda \Omega[1+4 a \theta \omega(1-a)]}{4 \Omega(1-a)(1+\beta)+\lambda \Omega[1+4 a \theta \omega(1-a)]+\lambda \sigma \omega(2 a-1)^{2}\left(1+2 \eta_{R} \chi\right)} \\
& \quad+\frac{\left[(1+\beta)\left[\Omega 4 a \theta(1-a)+\sigma(2 a-1)^{2}\right]+\sigma \eta_{R} \chi(2 a-1)[\lambda+2(1+\beta)]\right]}{4 \Omega(1-a)(1+\beta)+\lambda \Omega[1+4 a \theta \omega(1-a)]+\lambda \sigma \omega(2 a-1)^{2}\left(1+2 \eta_{R} \chi\right)} \mu_{y} .
\end{aligned}
$$

Next note that $\operatorname{det} \mathbf{C}<-1$ provided $\Gamma_{3}^{5}<\mu_{\pi}<\Gamma_{2}^{5}$, where

$$
\Gamma_{2}^{5} \equiv \frac{\Omega(1+\beta)+\left[\sigma \eta_{R} \chi(2 a-1)(1+\beta)+\left[\sigma(2 a-1)^{2}+4 a \theta \Omega(1-a)\right]\right] \mu_{y}}{2 \Omega(1-a)(1+\beta)+\lambda \sigma \omega \eta_{R} \chi(2 a-1)^{2}}
$$

Then $|\operatorname{tr} \mathbf{C}|<-1-\operatorname{det} \mathbf{C}$ implies $\Gamma_{1}^{5}<\mu_{\pi}<\Gamma_{4}^{5}$. Therefore, $\max \left\{0, \Gamma_{1}^{5}\right\}<\mu_{\pi}<\Gamma_{4}^{5}$, and either $\mu_{\pi}<\Gamma_{3}^{5}$ or $\Gamma_{3}^{5}<\mu_{\pi}<\Gamma_{2}^{5}$, are the necessary and sufficient conditions for the difference system. This completes the proof.

\section{References}

[1] ANDRÉS, J., LÓPEZ-SALIDO, J.D. and VALLÉS, J. (2006). Money in an estimated business cycle model of the Euro area. Economic Journal, 116, 457-477.

[2] ANDRÉS, J., LÓPEZ-SALIDO, J.D. and NELSON, E. (2009). Money and the natural rate of interest: structural estimates for the United States and the Euro area. Journal of Economic Dynamics and Control, 33, 758-776.

[3] AOKI, M. (1981). Dynamic Analysis of Open Economies. New York: Academic Press.

[4] BATINI, N. and HALDANE, A. (1999). Forward-looking rules for monetary policy. In J.B. Taylor (ed.), Monetary Policy Rules, Chicago, IL: Chicago University Press.

[5] BATINI, N., LEVINE, P. and PEARLMAN, J. (2004). Indeterminacy with inflationforecast-based rules in a two-block model. Board of Governors of the Federal Reserve System, International Finance Discussion Paper 797.

[6] BENHABIB, J. and EUSEPI, S. (2005). The design of monetary and fiscal policy: a global perspective. Journal of Economic Theory, 123, 40-73.

[7] BENHABIB, J., SCHMITT-GROHÉ, S. and URIBE, M. (2001). Monetary policy and multiple equilibria. American Economic Review, 91, 167-186. 
[8] BENiGnO, G. and BENIGNO, P. (2006). Designing targeting rules for international monetary policy cooperation. Journal of Monetary Economics, 53, 473-506.

[9] BENIGNO, G. and BENIGNO, P. (2008). Exchange rate determination under interest rate rules. Journal of International Money and Finance, 27, 971-993.

[10] BERGIN, P.R. (2006). How well can the New Open Economy Macroeconomics explain the exchange rate and current account? Journal of International Money and Finance, $\mathbf{2 5}, 675-701$.

[11] BERGIN, P.R., SHIN, H. and TCHAKAROV, I. (2007). Does exchange rate variability matter for welfare? A quantitative investigation of stabilization policies. European Economic Review, 51, 1041-1058.

[12] BERNANKE, B. and WOODFORD, M. (1997). Inflation forecasts and monetary policy, part 2. Journal of Money, Credit and Banking, 29, 653-684.

[13] BULLARD, J. and MITRA, K. (2002). Learning about monetary policy rules. Journal of Monetary Economics, 49, 1105-1129.

[14] BULLARD, J. and MITRA, K. (2007). Determinacy, learning and monetary policy inertia. Journal of Money, Credit and Banking, 39, 1177-1212.

[15] BULLARD, J. and SCHALING, E. (2009). Monetary policy, determinacy and learnability in a two-block world economy. Journal of Money, Credit and Banking, 41, $1585-1612$.

[16] CALVO, G. (1983). Staggered prices in a utility maximizing framework. Journal of Monetary Economics, 12, 383-398.

[17] CARLSTROM, C.T. and FUERST, T.S. (2001). Timing and real indeterminacy in monetary models. Journal of Monetary Economics, 47, 285-298.

[18] CLARIDA, R., GALÍ, J. and GERTLER, M. (1998). Monetary policy rules in practice: some international evidence. European Economic Review, 42, 1033-1067.

[19] CLARIDA, R., GALÍ, J. and GERTLER, M. (1999). The science of monetary policy. Journal of Economic Literature, 37, 1661-1707.

[20] CLARIDA, R., GALÍ, J. and GERTLER, M. (2000). Monetary policy rules and macroeconomic stability: evidence and some theory. Quarterly Journal of Economics, 115, $147-180$.

[21] CLARIDA, R., GALÍ, J. and GERTLER, M. (2002). A simple framework for international monetary policy analysis. Journal of Monetary Economics, 49, 879-904.

[22] COCHRANE, J.H. (2011). Determinacy and identification with Taylor rules. Journal of Political Economy, 119, 565-615. 
[23] DE FIORE, F. and LUI, Z. (2005). Does trade openness matter for aggregate instability? Journal of Economic Dynamics and Control, 29, 1165-1192.

[24] DE SCITOVSZKY, T. (1941). Capital accumulation, employment and price rigidity. Review of Economic Studies, 8, 69-88.

[25] DUFFY, J. and XIAO, W. (2011). Investment and monetary policy: learning and determinacy of equilibrium. Journal of Money, Credit and Banking, 43, 959-992.

[26] FRIEDMAN, M. (1968). The role of monetary policy. American Economic Review, 58, $1-17$.

[27] GALÍ, J. and MONACELLI, T. (2005). Monetary policy and exchange rate volatility in a small open economy. Review of Economic Studies, 72, 707-734.

[28] GIANNONI, M. and WOODFORD, M. (2005). Optimal inflation targeting rules. In B. Bernanke and M. Woodford (eds.), The Inflation Targeting Debate. Chicago, IL: Chicago University Press.

[29] HAMMOND, G. (2012). Handbook - no. 29: State of the art of inflation targeting 2012. Centre for Central Banking Studies, Bank of England.

[30] HUANG, K.X.D., MENG, Q. and XUE, J. (2009). Is forward-looking inflation targeting destabilizing? The role of policy's response to current output under endogenous investment. Journal of Economic Dynamics and Control, 33, 409-430.

[31] IRELAND, P.N. (2004). Money's role in the monetary business cycle. Journal of Money, Credit and Banking, 36, 969-983.

[32] KIRSANOVA, T., LEITH, C. and WREN-LEWIS, S. (2006). Should central banks target consumer prices or the exchange rate? Economic Journal, 116, F208-F231.

[33] KREMER, J., LOMBARDO, G. and WERNER, T. (2003). Money in a New-Keynesian model estimated with German data. Discussion Paper Series 1: Studies of the Economic Research Centre No. 15/2003, Deutsche Bundesbank.

[34] KUROZUMI, T. (2006). Determinacy and expectational stability of equilibrium in a monetary sticky-price model with Taylor rule. Journal of Monetary Economics, 53, $827-846$.

[35] LASAlle, J.P. (1986). The Stability and Control of Discrete Processes. New York, NY: Springer-Verlag.

[36] LEITH, C. and WREN-LEWIS, S. (2009). Taylor rules in the open economy. European Economic Review, 53, 971-995.

[37] LEVIN, A., WIELAND, V. and WILLIAMS, J.C. (2003). The performance of forecastbased monetary policy rules under model uncertainty. American Economic Review, 93, 622-645. 
[38] LINNEMANN, L. and SCHABERT, A. (2006). Monetary policy and the Taylor principle in open economies. International Finance, 9, 343-367.

[39] LLOSA, G. and TUESTA, V. (2008). Determinacy and learnability of monetary policy rules in small open economies. Journal of Money, Credit and Banking, 40, 1033-1063.

[40] MANKIW, G. and SUMMERS, L. (1986). Money demand and the effects of fiscal policies. Journal of Money, Credit and Banking, 18, 415-429.

[41] MCKNIGHT, S. (2011a). Investment and interest rate policy in the open economy. Oxford Economic Papers, 63, 673-699.

[42] MCKNIGHT, S. (2011b). Should central banks target consumer or producer prices? International Finance, 14, 445-479.

[43] MIHAILOV, A. (2006). Operational independence, inflation targeting, and UK monetary policy. Journal of Post Keynesian Economics, 28, 395-421.

[44] ORPHANIDES, A. (2001). Monetary policy rules based on real-time data. American Economic Review, 91, 964-985.

[45] ORPHANIDES, A. (2004). Monetary policy rules, macroeconomic stability, and inflation: a view from the trenches. Journal of Money, Credit and Banking, 36, 151-175.

[46] PATINKIN, D. (1949). The indeterminacy of absolute prices in classical economic theory. Econometrica, 17, 1-27.

[47] PATINKIN, D. (1956). Money, Interest, and Prices: An Integration of Monetary and Value Theory. Evanston, IL, and White Plains, NY: Row, Peterson and Company.

[48] PIERGALLINI, A. (2006). Real balance effects and monetary policy. Economic Inquiry, 44, 497-511.

[49] PIGOU, A.C. (1941). Employment and Equilibrium: A Theoretical Discussion. London: MacMillan.

[50] PIGOU, A.C. (1943). The classical stationary state. Economic Journal, 53, 343-351.

[51] RABANAL, P. and TUESTA, V. (2010). Euro-dollar real exchange rate dynamics in an estimated two-country model: an assessment. Journal of Economic Dynamics and Control, 34, 780-797.

[52] ROTEMBERG, J. and WOODFORD, M. (1997). An optimization-based econometric framework for the evaluation of monetary policy. In B. Bernanke and J. Rotemberg (eds.), NBER Macroeconomics Annual 199\%. Cambridge, MA: MIT Press.

[53] SCHABERT, A. and STOLTENBERG, C. (2005). Money demand and macroeconomic stability revisited. CEPR Discussion Paper No. 4974.

[54] STOLTENBERG, C. (2012). Real balance effects, timing, and equilibrium determination. Journal of Money, Credit and Banking, 44, 981-994. 
[55] SVENSSON, L.E.O. (1997). Inflation forecast targeting: implementing and monitoring inflation targets. European Economic Review, 41, 1111-1146.

[56] SVENSSON, L.E.O. (2003). What is wrong with Taylor rules? Using judgment in monetary policy through targeting rules. Journal of Economic Literature, 41, 426-477.

[57] TAYLOR, J.B. (1993). Discretion versus policy rules in practice. Carnegie-Rochester Conference Series on Public Policy, 39, 195-214.

[58] TAYLOR, J.B. (2001). The role of the exchange rate in monetary policy rules. American Economic Review, 91, 263-267.

[59] TAYLOR, J.B. and WILLIAMS, J.C. (2010). Simple and robust rules for monetary policy. In B. M. Friedman and M. Woodford (eds.), Handbook of Monetary Economics, Vol. 3. Amsterdam, North Holland: Elsevier.

[60] VON HABERLER, G. (1937). Prosperity and Depression: A Theoretical Analysis of Cyclical Movements. Geneva: League of Nations.

[61] WALSH, C.E. (2003). Speed limit policies: the output gap and optimal monetary policy. American Economic Review, 93, 265-278.

[62] WOODFORD, M. (2001). The Taylor rule and optimal monetary policy. American Economic Review, 91, 232-237.

[63] WOODFORD, M. (2003a). Interest Rates and Prices: Foundations of a Theory of Monetary Policy. Princeton, NJ: Princeton University Press.

[64] WOODFORD, M. (2003b). Optimal interest-rate smoothing. Review of Economic Studies, 70, 861-886.

[65] ZANNA, L.-F. (2003). Interest rate rules and multiple equilibria in the small open economy. International Finance Discussion Papers 785, Board of Governors of the Federal Reserve System. 